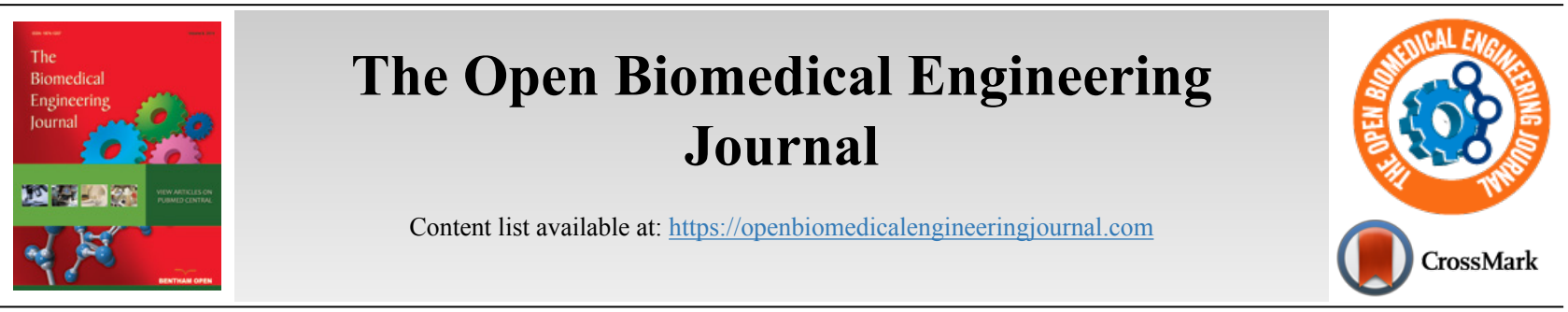

REVIEW ARTICLE

\title{
In vitro Biomodels in Stenotic Arteries to Perform Blood Analogues Flow Visualizations and Measurements: A Review
}

Violeta Carvalho, ${ }^{1, *}$ Inês Maia ${ }^{2}$, Andrews Souza ${ }^{3}$, João Ribeiro ${ }^{3,4}$, Pedro Costa $^{5}, \mathrm{H}_{\text {. Puga }}^{6}$, Senhorinha Teixeira ${ }^{7}$ and Rui A. Lima $^{1,8}$

${ }^{1}$ METRICS, Minho University, Guimarães, Portugal

${ }^{2}$ Instituto Superior Técnico, Universidade de Lisboa, Lisboa, Portugal

${ }^{3}$ Instituto Politécnico de Bragança, Bragança, Portugal

${ }^{4}$ CIMO, Instituto Politécnico de Bragança, Bragança, Portugal

${ }^{5}$ BIOFABICS, Rua Alfredo Allen 455, 4200-135, Porto, Portugal

${ }^{6}$ CMEMS, Minho University, Guimarães, Portugal

${ }^{7}$ Algoritmi, Minho University, Guimarães, Portugal

${ }^{8}$ CEFT, Faculty of Engineering of the University of Porto, Porto, Portugal

\begin{abstract}
:
Cardiovascular diseases are one of the leading causes of death globally and the most common pathological process is atherosclerosis. Over the years, these cardiovascular complications have been extensively studied by applying in vivo, in vitro and numerical methods (in silico). In vivo studies represent more accurately the physiological conditions and provide the most realistic data. Nevertheless, these approaches are expensive, and it is complex to control several physiological variables. Hence, the continuous effort to find reliable alternative methods has been growing. In the last decades, numerical simulations have been widely used to assess the blood flow behavior in stenotic arteries and, consequently, providing insights into the cardiovascular disease condition, its progression and therapeutic optimization. However, it is necessary to ensure its accuracy and reliability by comparing the numerical simulations with clinical and experimental data. For this reason, with the progress of the in vitro flow measurement techniques and rapid prototyping, experimental investigation of hemodynamics has gained widespread attention. The present work reviews state-of-the-art in vitro macro-scale arterial stenotic biomodels for flow measurements, summarizing the different fabrication methods, blood analogues and highlighting advantages and limitations of the most used techniques.
\end{abstract}

Keywords: Blood analogues, Blood flow, Cardiovascular diseases, Flow measurements, Hemodynamics, In vitro, Rapid prototyping, Stenosis.

\begin{tabular}{l|l|l|l}
\hline Article History & Received: August 4, 2020 & Revised: November 10, 2020 & Accepted: November 13, 2020
\end{tabular}

\section{INTRODUCTION}

Cardiovascular Diseases (CVDs) are the most common reason for death and they are considered to be one of the most important problems related to human health worldwide. According to the World Health Organization (WHO) data, 17.9 million people died from CVDs in 2016, representing $31 \%$ of all global deaths [1]. In order to reduce these numbers, several research works have been done over the years. Although the initial research incorporated mostly simpler cases of study, more realistic research has been applied to different cardiovascular analyses, including studies conducted on blood vessels [2], aneurysms [3, 4] and stenotic arteries [5, 6]. Nevertheless, according to the literature [7], CVDs are mainly

\footnotetext{
* Address correspondence to this author at the Minho University, Braga,
} Portugal; E-mail: violeta.carvalho@dem.uminho.pt caused by atherosclerosis, and, therefore, will be the focus of this work. Atherosclerosis is a complex pathological process characterized by the gradual formation of lipid-containing plaques in the innermost layer of the arterial wall that narrows its lumen (Fig. 1) [8 - 11]. There are several factors that influence the development of atherosclerosis, however, the lack of exercise, smoking, obesity, and a fatty diet appear to increase the severity of atherosclerosis and the rate at which it develops $[12,13]$. In this pathology, as the lumen narrowing increases, resistance to blood flow is significantly increased and, consequently, normal circulation to tissues is hampered. This increases the work that the heart must perform, and can cause fatal cardiovascular events $[8,14]$.

To understand the pathology process associated with atherosclerosis, many hemodynamic studies have been conducted [15 - 21], either in vitro, in vivo, in silico or ex vivo, with the purpose to obtain detailed pressure and velocity fields 
of blood flow phenomena, and many efforts have been made to accurately perform the early detection of this pathology, namely in carotid artery stenosis as shown in detail in a recent review conducted by Saxena et al. [13].

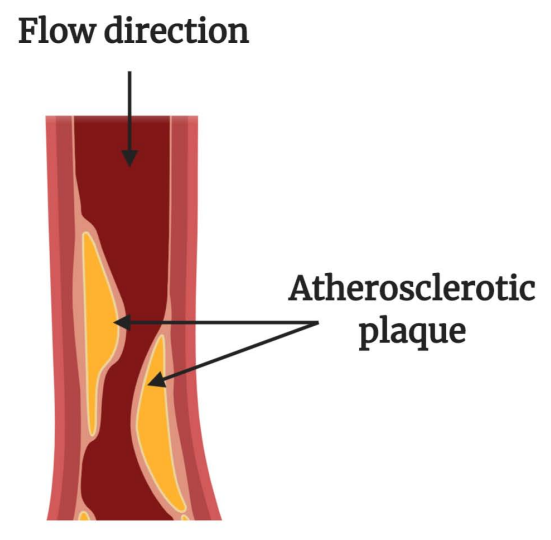

Fig. (1). Schematic representation of atherosclerotic plaque.

The primary technique used to characterize the flow field in the major blood vessels was performed by Dokunin et al. [22], in the mid of $19^{\text {th }}$ century, when the extremities of a known volume airtight U-tube was connected to a blood vessel to measure the rate of arterial blood flow according to the Poiseuille formula. Nowadays, in vivo blood flow measurements are acquired through non-invasive techniques that include computed tomography (CT) [23], doppler [21, 24, 25], ultrasound [26], phase-contrast magnetic resonance imaging (PC-MRI) [27, 28], among others. Despite such measurements having the potential to provide the most realistic flow field data, there are technical difficulties such as long measuring times and lack of spatial resolution to derive velocity gradients and wall shear stresses, which limit the representation of the vessel geometry, blood and tissue properties $[17,29,30]$. To overcome these limitations, some recent studies have been performed. For instance, Chayer et al. [31] proposed a method to manufacture ultrasonic vascular biomodels with realistic geometries and mechanical properties that mimic the atheromatous plaque in a carotid artery bifurcation. This method can be useful to validate new ultrasound-based imaging technologies, and also for fluidstructure experimental modeling. Goudot et al. [32] showed the ability of ultrafast ultrasound imaging to evaluate local flow velocities over an entire 2D image, which allowed the obtention of accurate measurements of wall shear stress (WSS) when compared to conventional ultrasound imaging. Although research has progressed to overcome the difficulties of in vivo measurements, these methods are still expensive, have low reproducibility, and require ethical and regulatory considerations [33, 34].

An alternative to those measurements is in vitro experiments, which have captured the attention of many researchers and, thus, they have been improved over the years. Several techniques, including laser doppler anemometry [35], video microscopy and image analysis [36] and particle-based methods such as particle image velocimetry (PIV) [37, 38], micro-particle image velocimetry ( $\mu \mathrm{PIV})$ [39], particle tracking velocimetry (PTV) [40] and stereo-PIV [41], have been applied for in vitro blood flow studies. Although these studies do not accurately replicate the complex interactions that occur in vivo, they provide an excellent alternative to control experimental variables and they are an important tool to validate and complement numerical studies [42].

Another relevant approach is ex vivo studies. These studies bridge the gap between in vitro and in vivo research, where whole tissue slices are cultured [42, 43]. For instance, about two decades ago, Santamore et al. [44] studied the effect of stenosis on arterial vasoconstriction. For that purpose, the authors used portions of the proximal circumflex artery of five dogs. More recently, Karimi et al. [19] aimed to characterize the mechanical properties of human coronary arteries and then to assess the plaque vulnerability based on peak plaque stress. To this end, they studied both atherosclerotic and healthy human coronary arteries, excised within $5 \mathrm{~h}$ postmortem. Their primary results allowed to verify that the atherosclerotic coronary arteries have significantly higher stiffness in comparison to healthy ones.

In addition to the previous methodologies, another powerful research tool for atherosclerosis investigation emerged with the rapid advances in computer technology, computational simulations [45]. In particular, computational fluid dynamics (CFD) have attracted many researchers to investigate in detail several blood flow phenomena in blood vessels, which are difficult to study in detail either in vitro or in vivo [46 - 52]. For instance, researchers with expertise in numerical methods have studied several elasticity models to physiologically mimic the artery walls [53, 54]. However, the validity of the elasticity models should be tested by taking into account medical observations. In addition, to these elasticity models, other researchers have tested fluid-structure interaction (FSI) models to study the interaction of the blood flow with the vessel wall [55 - 57], where several researchers have performed the comparison between FSI and CFD studies [58, 59]. For instance, Lopes and his team [58] compared both methods and verified that it is fundamental to consider the artery wall as an elastic body, since the rigid model overestimates the flow velocity and WSS. From another perspective, Saxena and coworkers [60] conducted an innovative study where the effect of carotid artery stenosis on the neck skin temperature maps was investigated. From the computational results, it was observed that in the presence of a stenosis, a relatively lower temperature region occurs on the section of the carotid artery wall over the stenosis tissue. Even so, there are still several problems and challenges related to the performance of realistic blood flow modeling and, therefore, numerical models are not able to completely replace experimental tests [61]. For this reason, the combination of numerical and experimental methods has been a valuable tool [62 - 65]. In Table 1, some advantages and disadvantages of these different assumptions, in vivo, in vitro, ex vivo, and in silico are summarized. More detailed information about the evolution and importance of numerical methods in atherosclerosis investigation can be found elsewhere [66, 67]. 
Table 1. Advantages and disadvantages of in vivo, in vitro, ex vivo, and in silico studies.

\begin{tabular}{|c|c|c|c|}
\hline & Advantages & Disadvantages & Ref. \\
\hline In vivo & $\begin{array}{l}\text { More realistic data; } \\
\text { Good to validate new practices and techniques. }\end{array}$ & $\begin{array}{c}\text { Difficult to control variables; } \\
\text { Difficult to visualize; } \\
\text { Long measuring times; } \\
\text { Insufficient resolution; } \\
\text { Expensive; } \\
\text { Low reproductively; } \\
\text { Ethical issues. }\end{array}$ & {$[17,30,68,69]$} \\
\hline In vitro & $\begin{array}{l}\text { Easy to control variables; } \\
\text { Easy to visualize; } \\
\text { Low-cost; } \\
\text { Good to validate numerical studies; } \\
\text { Reduce the use of animals; } \\
\text { Do not have ethical issues. }\end{array}$ & $\begin{array}{l}\text { Difficult to measure some variables (e.g., WSS); } \\
\text { Do not represent the complexity that happens in vivo; } \\
\text { Critical to reproduce exact geometry; } \\
\text { Difficult to reproduce real wall motion. }\end{array}$ & {$[42,62,70]$} \\
\hline Ex vivo & $\begin{array}{l}\text { No post-surgical animal care; } \\
\text { Maintain the architecture of the tissues closer to the in vivo } \\
\text { setting; } \\
\text { Moderate control of variables; } \\
\text { Better visualization compared to in vivo. }\end{array}$ & $\begin{array}{c}\text { Short observation time; } \\
\text { Difficult to visualize; } \\
\text { The age of the models may represent a critical factor; } \\
\text { Isolation of the arteries is a critical process; } \\
\text { Ethical issues. }\end{array}$ & {$[42,71]$} \\
\hline In silico & $\begin{array}{c}\text { Construction of more realistic virtual models; } \\
\text { Reduction of lead times and costs of new designs and greater } \\
\text { detail of the results; } \\
\text { Complement experimental and clinical approaches; } \\
\text { Ability to simulate biofluid flows } \\
\text { that are not reproducible in experiments. }\end{array}$ & $\begin{array}{c}\text { Difficult to define mathematically some physiological and } \\
\text { biological parameters; } \\
\text { Require experimental validation; } \\
\text { The results are dependent on the accuracy of the mesh } \\
\text { performed; } \\
\text { Complex simulations can be very long. }\end{array}$ & {$[45,70,72,73]$} \\
\hline
\end{tabular}

Despite the large variety of methods to understand the pathology of atherosclerosis previously mentioned, recent advances in computer-aided design (CAD), medical imaging, and $3 \mathrm{D}$ printing technologies have provided a rapid and costefficient method to generate arterial stenotic biomodels, making in vitro studies a valuable and powerful tool. In this regard, the main aim of this review was to provide a critical evaluation of different $3 \mathrm{D}$ printing approaches to manufacture in vitro biomodels of stenotic arteries to perform measurements and flow visualizations with techniques commonly used.

\section{MAIN STEPS INVOLVED IN THE FABRICATION OF IN VITRO BIOMODELS}

To obtain the biomodels for performing in vitro studies, three major steps must be taken, which are represented in Fig. (2).

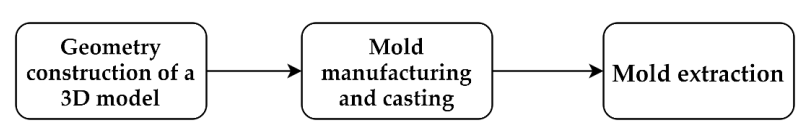

Fig. (2). Schematic representation of general steps involved in the fabrication of in vitro biomodels.

Initially, the design of the blood vessel under study is performed and this can be obtained from either patient-specific $[17,18,33,38,74-77]$ or idealized geometries [2, 16, 37, 62, 78 - 83]. After the geometry construction, a negative mold of the lumen is manufactured. To this end, there are many manufacturing methods available, but the most common is rapid prototyping.

Rapid prototyping, also named additive manufacturing, is the latest innovative technology that has revolutionized product design, manufacturing, and biomedical engineering, in the development of in vitro biomodels $[84,85]$. This technique allows the rapid conversion of the information from computerized 3D solid models into physical objects in a layerby-layer manner [85 - 87].

Over the last decades, several rapid prototyping techniques that involved the processing of materials in solid, powder, or liquid form have been developed [84]. In Fig. (3), the main rapid prototyping techniques are outlined and methods such as Stereolithography (SLA), Digital Light Processing (DLP), Multijet Modeling (MJM), Fused Deposition Modeling (FDM), Selective Laser Sintering (SLS), Electron Beam melting (EBM), Direct Metal Laser Sintering (DMLS), Inkjet 3D printing, and Laminated Object Manufacturing (LOM) are included.

Despite the numerous types of 3D printers encountered in the market, the SLA, FDM, Inkjet, and Multijet techniques are the most commonly used to manufacture stenotic artery physical models.

Briefly, in SLA, an object is created layer-by-layer and the polymer resin is cured by photopolymerization using an ultraviolet (UV) laser beam [88]. At each layer, the laser is moved, tracing a pattern, and solidifying the resin [86].

In the FDM technique, an object is built by extruding a liquid thermoplastic material from a movable printer nozzle and then deposited layer-by-layer onto a substrate. After extrusion, the thermoplastics solidify almost immediately [86]. For instance, Faria et al. [89] and Hütter et al. [90] made 3D biomodels for flow visualizations using FDM printers. 


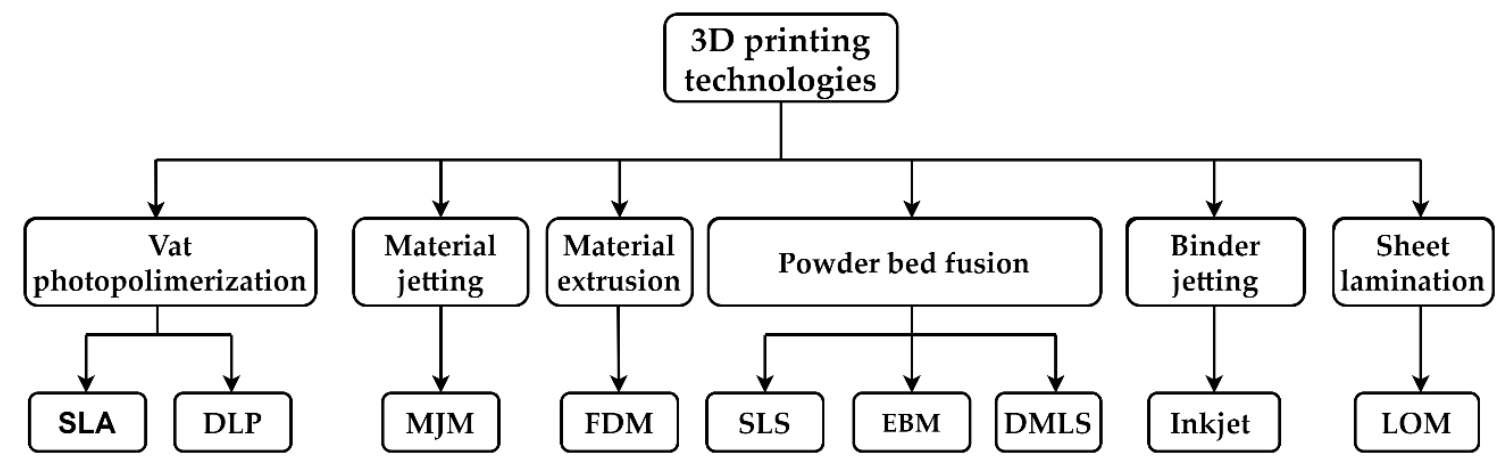

Fig. (3). A comprehensive list of the major rapid prototyping techniques that are currently in use for several biomedical applications.

The Inkjet process uses a liquid binding agent and a powder-based material. The printhead selectively drops a fixed quantity of the liquid binding agent. The ejected droplet falls under the action of gravity into the substrate and then dries through solvent evaporation. Then, a piston lowers the powder bed so that a new layer of powder can be spread over the surface of the previous layer. This process is repeated until the 3D structure is finished. In addition, this process can print a variety of materials such as metals, ceramics, and polymers $[86,91]$. Aycok et al. [92] used this technology to produce a healthy inferior vena cava, and they showed that this technique is suitable to obtain optically transparent internal flow biomodels.
Multijet printing works similarly to traditional inkjet printing, but instead of jetting ink onto a powder-based material, a jetting head deposits liquid photopolymer droplets onto a build platform where each droplet cures with a UV light. After building each layer, UV light hardens the layer, and the build platform moves down in the $z$-direction so that the next layer can be printed [85]. Table 2 shows the advantages and disadvantages of these techniques to manufacture arterial biomodels. Additionally, Table 3 presents some hemodynamic in vitro studies that have used $3 \mathrm{D}$ printing technologies to manufacture stenotic biomodels, and the respective geometry, cast material, blood analogues, and the measurement method used.

Table 2. Advantages and disadvantages of the most common 3D printing techniques used to produce arterial biomodels.

\begin{tabular}{|c|c|c|}
\hline Methods & Advantages & Disadvantages \\
\hline SLA & $\begin{array}{c}\text { Simple manufacturing process; } \\
\text { Fast and good resolution. }\end{array}$ & $\begin{array}{c}\text { Expensive equipment and materials; } \\
\text { Only photopolymers. }\end{array}$ \\
\hline \multirow{3}{*}{ FDM } & $\begin{array}{c}\text { Easy to use; } \\
\text { Good mechanical properties; } \\
\text { Low-cost; } \\
\text { FultiJet }\end{array}$ & $\begin{array}{c}\text { Materials limited to thermoplastics; } \\
\text { Low resolution. }\end{array}$ \\
& Fast and scalable; & Poor mechanical properties; \\
& Smooth surface finish; & Expensive. \\
Inkjet & High resolution. & Low resolution; \\
& Low cost; & Easy to use; \\
& Reasonably fast. & Low mechanical properties; \\
& & Expensive replacement ink cartridges.
\end{tabular}

Table 3. Summary of some in vitro hemodynamic studies using 3D printed biomodels.

\begin{tabular}{|c|c|c|c|c|c|c|}
\hline Geometry & $\mathbf{R P}^{1}$ system & RP material & Cast material & Blood analogue & $\begin{array}{c}\text { Measurement } \\
\text { method }\end{array}$ & Ref \\
\hline $\begin{array}{c}\text { Real porcine coronary } \\
\text { arteries }\end{array}$ & $\begin{array}{c}\text { Multijet and } \\
\text { Inkjet }\end{array}$ & FullCure ${ }^{\circledR} 720$ and $3 \mathrm{Z}$ model & $\mathrm{PDMS}^{2}$ & $\mathrm{~W}^{3}$ & - & {$[76]$} \\
\hline Idealized & $\begin{array}{l}\text { Injection } \\
\text { molding }\end{array}$ & Aluminum & \begin{tabular}{|c|}
$\begin{array}{c}\text { Silicone (T-2 } \\
\text { silastic) }\end{array}$ \\
\end{tabular} & W- $\mathrm{G}^{4}(40,60 \%)$ & PIV & {$[93]$} \\
\hline $\begin{array}{c}\text { Idealized and Patient- } \\
\text { specific } \\
\end{array}$ & $\mathrm{SLA}^{5}$ & Epoxy resin & PDMS & $\mathrm{DMSO}^{6}-\mathrm{W}(52,48 \%)$ & $\mu \mathrm{PIV}$ & {$[75]$} \\
\hline Patient-specific & SLA & PIC100 resin & PDMS & Whole blood & $\begin{array}{c}\text { Fluorescence } \\
\text { microscopy }\end{array}$ & $\mid[77]$ \\
\hline
\end{tabular}


(Table 3) contd....

\begin{tabular}{|c|c|c|c|c|c|c|}
\hline Geometry & RP ${ }^{1}$ system & RP material & Cast material & Blood analogue & $\begin{array}{l}\text { Measurement } \\
\text { method }\end{array}$ & Ref \\
\hline Patient-specific & SLA & $\begin{array}{c}\text { VeroWhitePlus RGD835 and } \\
\text { TangoPlus FLX930 }\end{array}$ & Silicone & $\begin{array}{c}\mathrm{DiW}^{7}-\mathrm{G}-\text { corn starch } \\
(70,30,0.1 \%)\end{array}$ & Doppler & {$[94]$} \\
\hline Patient-specific & $\begin{array}{l}\text { SLA; Multijet } \\
\text { and FDM }\end{array}$ & $\begin{array}{c}\text { Flexible resin, Tango Grey, } \\
\text { TangoBlack and TPU } \\
\text { filament }\end{array}$ & - & - & $\mathrm{CT}$ & {$[95]$} \\
\hline Patient-specific & Inkjet & $\begin{array}{l}\text { Low melting } \\
\text { point alloy }\end{array}$ & Silicone & $\begin{array}{l}\text { G- SNDS }{ }^{9}-D^{10}-\mathrm{O}^{11}- \\
\text { Antifungal agent- DM } \\
{ }^{12}(15,1,3,2,79 \%)\end{array}$ & Doppler Ultrasound & {$[96]$} \\
\hline Idealized & SLA & Epoxy resin & PDMS & W-G $(39,61 \%)$ & $\mu \mathrm{PIV}$ & {$[83]$} \\
\hline Idealized & FDM & $\mathrm{ABS}^{13}$ filaments & PDMS & $\begin{array}{c}\text { DiW-G-NaI }{ }^{14}(47.38 \\
36.94,15.68 \%)\end{array}$ & PIV & {$[15]$} \\
\hline Idealized & SLA & Clear resin & PDMS & $\mathrm{D}$ & $\begin{array}{l}\text { Inverted confocal } \\
\text { microscope }\end{array}$ & {$[97]$} \\
\hline Patient-specific & Inkjet & Water-soluble plaster & Silicone & W-G $(45,55 \%)$ & PIV & {$[17]$} \\
\hline Patient-specific & SLA & Stereocol Acrylate & RTV $^{15}$ Silicone & $\mathrm{IA}^{16}-\mathrm{G}(70,30 \%)$ & PIV & {$[18]$} \\
\hline Idealized & SLA & - & - & DMSO-W $(52,48 \%)$ & PTV & [63] \\
\hline
\end{tabular}

${ }^{1} \mathrm{RP}$ - Rapid Prototyping, ${ }^{2}$ Polydimethylsiloxane, ${ }^{3} \mathrm{~W}$-water, ${ }^{4} \mathrm{G}$-Glycerol, ${ }^{5} \mathrm{SLA}$ - Stereolithography, ${ }^{6} \mathrm{DMSO}$ - Dimethyl sulfoxide, ${ }^{7}$ DiW- Distilled water, ${ }^{8} \mathrm{TPU}-$ Thermoplastic polyurethane, ${ }^{9} \mathrm{SND}$ - Synperonic N detergent surfactant, ${ }^{10} \mathrm{D}$-Dextran, ${ }^{11} \mathrm{O}$-Orgasol particles, ${ }^{12} \mathrm{DM}$ - Demi water, ${ }^{13} \mathrm{Acrylonitrile}$ butadiene styrene, ${ }^{14} \mathrm{NaI}$ Sodium iodide, ${ }^{15}$ RTV-Room-Temperature-Vulcanizing, ${ }^{16}$ IA-Isopropyl alcohol

Finally, to cast the physical model, transparent material to the applied wavelength light must be used and its half thickness must be smaller than the focal distance of the used objective lens [98]. Initially, different materials were used, like plastic [99], glass [100, 101], latex [102], polymethylmethacrylate (PMMA) [103, 104] and Agar-based materials [105]. Despite the diversity of materials mentioned, the most common transparent materials are polydimethylsiloxane (PDMS), glass, and PMMA. However, over time, PDMS became the preferred material of researchers due to its superior properties when compared to the remaining materials [106 - 108]. Some advantages and disadvantages of PDMS, PMMA, and glass are summarized in Table 4. In turn, Table 5 summarizes the typical mechanical, chemical (solvent and acid/base resistance), and material costs of those materials, commonly used in in vitro studies.

Table 4. Advantages and disadvantages of some casting materials used in biomodels.

\begin{tabular}{|c|c|c|}
\hline & Advantages & Disadvantages \\
\hline PDMS & \begin{tabular}{|c|} 
Nontoxicity; \\
Biocompatibility; \\
Gas permeability; \\
Simple fabrication process; \\
Good optical transparency; Durability; \\
Elasticity; \\
Capable of sustaining a variety of cell types; \\
Inert. \\
\end{tabular} & $\begin{array}{l}\text { Can absorb small hydrophobic molecules; } \\
\text { Evaporation of water vapor is hard to control; } \\
\text { Hydrophobic nature. }\end{array}$ \\
\hline PMMA & $\begin{array}{l}\text { Economic; } \\
\text { Biocompatibility; } \\
\text { Ease of processing. }\end{array}$ & $\begin{array}{l}\text { Rigid; } \\
\text { Can undergo thermal degradation and thermal oxidative degradation in the presence of } \\
\text { oxygen. }\end{array}$ \\
\hline Glass & $\begin{array}{l}\text { Good optical transparency; } \\
\text { Excellent roughness; } \\
\text { Inert. }\end{array}$ & $\begin{array}{l}\text { Difficult to reproduce the desired geometry; } \\
\text { Rigid. }\end{array}$ \\
\hline
\end{tabular}

Table 5. Summary of physical properties for common polymers used in in vitro models.

\begin{tabular}{|c|c|c|c|}
\hline & PDMS & PMMA & Glass \\
\hline Mechanical properties & Elastomer & Rigid & Rigid \\
\hline Solvent resistance & Poor & Good & Excellent \\
\hline $\begin{array}{c}\text { Optical transmissivity } \\
\cdot \text { Visible range } \\
\cdot \text { UV range }\end{array}$ & $\begin{array}{c}\text { Excellent } \\
\text { Good }\end{array}$ & $\begin{array}{l}\text { Excellent } \\
\text { Good }\end{array}$ & $\begin{array}{l}\text { Excellent } \\
\text { Good }\end{array}$ \\
\hline Biocompatibility & Good & Good & Good \\
\hline Material cost & $\sim 135 € / \mathrm{Kg}$ & $\sim 1.6-3.6 € / \mathrm{Kg}$ & $\sim 20-30 € / \mathrm{Kg}$ \\
\hline
\end{tabular}


Although PDMS is the most well-known and common method, some authors have tried to directly print biomodels without using cast materials in order to produce compliant biomodels [74, 95]. For instance, Biglino et al. [74] used the multijet technique to obtain compliant arterial biomodels of patient-specific data. They concluded that TangoPlus

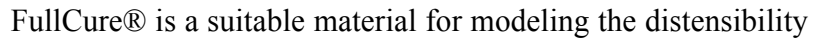
of arteries in vitro with very representative anatomical finishing and with the ability to represent non-uniform wall thickness. More recently, another interesting study was carried out by Stepniak et al. [95]. They have used four flexible commercially available materials (Table 3 ) to print 3D flexible plaque biomodels that accurately recapitulate the physiology and geometry of stenotic coronary arteries. In this study, it was shown that non-calcified plaques can be defined as lipid-rich or fibrous according to their measured CT number. Taking this assumption, the authors aimed to study whether the $3 \mathrm{D}$ printing materials would be appropriate for lipid-rich and fibrous plaque biomodels when using a contrast agent and standard Computed Tomography Coronary Angiography (CTCA) protocol. They have found that SLA and Polyjet technology allowed to obtain hollow models, whereas the $\mathrm{CT}$ numbers having samples with wall thickness between 0.7 and $1.7 \mathrm{~mm}$ were found to mimic lipid-rich plaque. The use of these biomodels can be important for optimizing CTCA protocol by exploring the effect of arterial geometry, degree of stenosis, and motion on CT number measurements.

Although several researchers have used 3D printing to directly obtain biomodels to visualize flows, there is still a long way to produce biomodels able to mimic in vivo arteries. However, from the gathered literature, it was found that the more used $3 \mathrm{D}$ printing techniques are SLA and Inkjet combined with PDMS as the cast material, whereas PIV is the preferred method to perform flow visualization measurements. Regarding the blood analogues, it can be seen that there is a wide diversity, showing that this field of research is still at an early stage of development.

\section{IN VITRO STUDIES IN STENOTIC ARTERIES}

Over the years, several researchers have been investigating different parameters associated with atherosclerosis through in vitro techniques in order to better understand this pathology and find new therapies or improve the existing ones. This section shows an overview of several relevant existing studies of stenotic arteries employing in vitro methods.

\subsection{Coronary Arteries}

In the last few years, Doutel's research group has studied stenotic coronary arteries both numerically and experimentally by using a $\mu$ PIV $[75,83,109]$. In one of these studies [83], the main purpose was to obtain a sequential method to fabricate transparent PDMS models from a mold produced by rapid prototyping (Fig. 4A). In this study, they compared two types of casting methods (lost-wax and sucrose), since the removal process of these materials can compromise the optical flow experiments and the credibility of the final results. They observed that for the lost-wax method, the channels tend to become contaminated during the removal process. In contrast, the lost-sucrose casting method exhibited much better optical characteristics and, as a result, has improved the flow visualizations.

From a different perspective, Doutel et al. [109] developed a methodology to create three-dimensional irregular stenosis with different degrees of occlusion in artery models for numerical and in vitro hemodynamic studies, identifying areas of low WSS since these locations have more propensity to the development of atherosclerosis. The results obtained showed that the irregular shape of the stenosis and its morphology affect the flow field, creating different values of WSS for each case. In general, this method showed to be a fast and effective tool to generate realistic stenotic models suitable for hemodynamic studies, which are very useful in this field of research. In another study [75], by applying the fabrication process previously described [83], they investigated, in vitro and in silico, the geometrical effects on blood flow by comparing both idealized and patient-specific models of a left coronary artery with no signs of the disease and two derived models (one planar and another non planar). By using these models, they studied the influence of non planarity in hemodynamics. In addition, they applied the previous methodology [109] and created irregular stenotic models. In general, they have verified that the patient-specific geometry presented asymmetric stenosis, while the ideal cases led to smooth and symmetric stenosis. Accordingly, patient $\square$ specific models should be used for hemodynamic studies whenever possible. It was also demonstrated that eccentricity is an important parameter since its variations along the branches lead to asymmetric flow patterns (Fig. 4B). In addition, they have concluded that the non planarity does not influence the formation of the stenosis, however, it has an unquestionable effect in helicity. An increase in the helical flow was observed when the flow is forced to change its direction following the curvatures induced by the non planarity.

Another recent and interesting study in stenotic coronary arteries was conducted by Carvalho et al. [63]. In their study, they investigated not only the influence of printing resolution in the flow visualizations by using an SLA 3D printer and a PTV system but also the stenosis effect in the flow behavior, both experimentally and numerically. The results showed that the biomodels printed with a resolution of $50 \mu \mathrm{m}$ allowed to visualize more accurately the blood analogue flow due to the lowest roughness values measured in those biomodels. Additionally, the flow experimental results showed to be in good agreement with the blood flow numerical data, with the appearance of recirculation regions when the diameter reduces $60 \%$, which were significantly higher in the $80 \%$ stenosis model (Fig. 4C). 
A

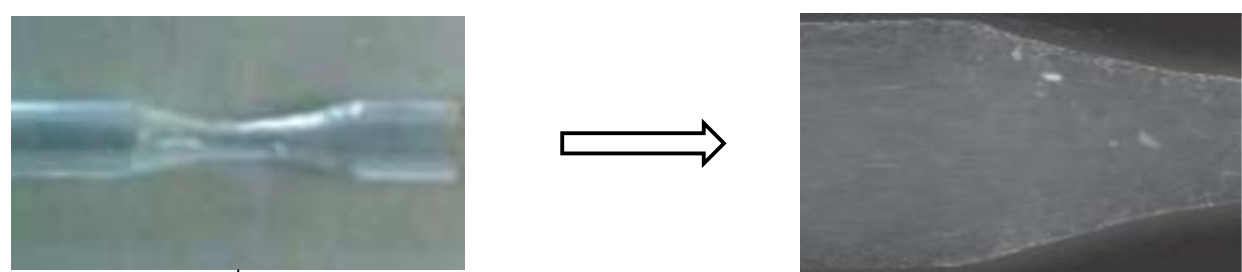

PDMS channel with $75 \%$ occlusion

B
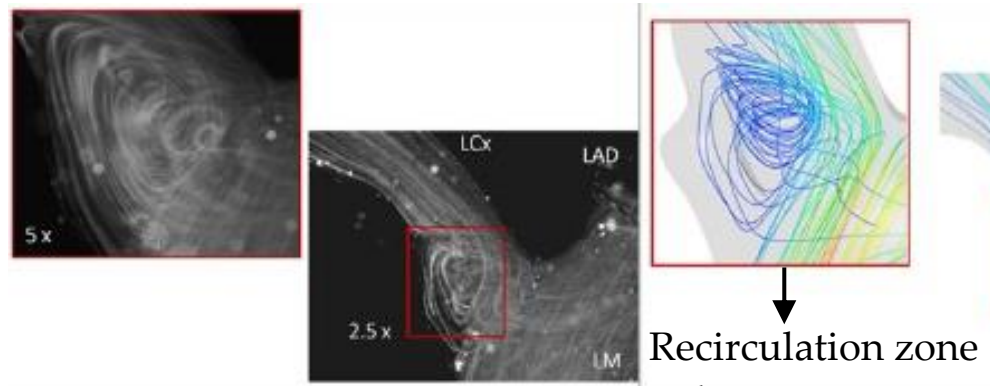

due to stenosis

C

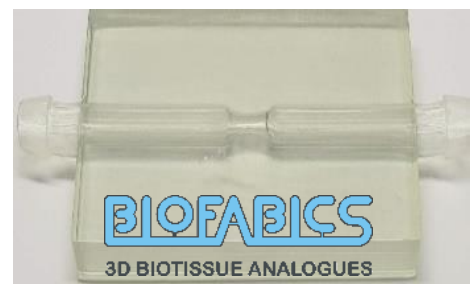

D

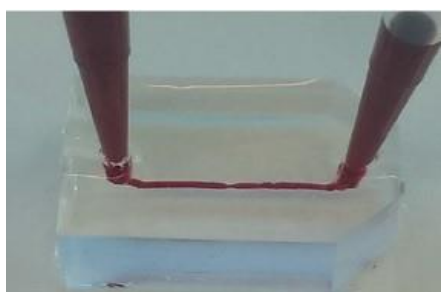

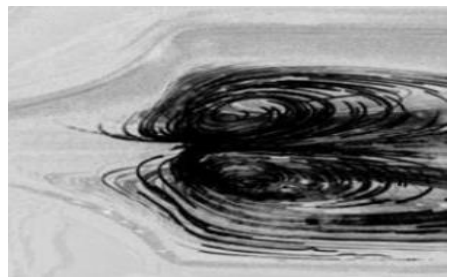

Recirculation zones observed experimentally in the $80 \%$ stenotic

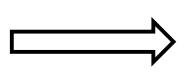

\section{Visualization of the}

channel with cells

Fig. (4). Examples of some biomodels and respective experimental images: A) Rigid PDMS phantom and flow visualization of a stenotic artery, adapted from [83]; B) Flow visualization and streamlines obtained numerically of a stenotic left coronary artery, adapted from [75]; C) Stenotic model fabricated by Biofabics and the recirculation zones observed experimentally, adapted from [63]; D) PDMS model of a stenotic coronary artery and image obtained by means of fluorescence microscopy, adapted from [77].

In a recent study conducted by Jewkes et al. [76] 3D models of healthy and diseased coronary arteries were fabricated based on a porcine heart and defined based on morphometric measurements. Two different printers were used and compared through the evaluation of different parameters such as layer thickness, anatomical accuracy, and time per model. In their investigation, a wax model was printed around (or within) where PDMS was set. This method showed to be valuable for experimental testing and may enable the replication of the artery thickness during the manufacturing process, which is important to better mimic the physiology of the arteries. Regarding the hemodynamics, they verified the presence of helical flow patterns in healthy models, and recirculation zones were observed in all biomodels. Note that these recirculation zones were quite larger at the stenotic models. Although this study gives useful information about the manufacturing process, some limitations can be pointed out. For instance, water was used as the working fluid and all flow measurements were recorded with a mobile phone. These features can compromise and turn the results less accurate.

In another investigation, Yang et al. [110] studied patientspecific left coronary stenotic arteries. They performed numerical studies and used 3D printing technologies (SLA) for a comprehensive understanding of the relationship between spatial characteristics and hemodynamics variations, which include the severity of stenosis, locations of the lesions, the 
angle of the bifurcation at immediate upstream, and the angle of the culprit's vessel, the curvature of the bifurcations. The results showed that multiple spatial characteristics can be an index of hemodynamics significance and they can potentially improve the non-invasive evaluation of the diseased vessel.

Since atherosclerosis is a complex disease associated with multiple factors, other promising studies have emerged [111 114] to understand the process of atherogenesis, thrombus formation, and cell interactions in stenotic arteries. In this direction, an interesting study was undertaken by Costa et al. [77]. Combining SLA 3D printing with real medical images and fluorescence microscopy, they performed both in vitro and in silico flow studies through healthy and stenotic arteries in order to study thrombosis (Fig. 4D). The fabricated channels were lined with endothelial cells and perfused with recalcified citrated human whole blood. They compared the healthy and stenotic geometries with different degrees of occlusion and they have observed that after 15 minutes of perfusion, the healthy geometries have shown no sign of thrombosis, while the stenotic geometries have induced thrombosis at the stenotic region. By using this methodology, thrombosis can be mimicked in 3D vessel geometries and it can be an important step towards patient-specific arterial thrombosis studies.

\subsection{Carotid Arteries}

Interesting studies in stenotic carotid bifurcation arteries have been conducted by Kefayati et al. [82, 115, 116], combining PIV analysis with CFD simulations. Firstly, the researchers only considered healthy and stenotic carotid arteries $(50 \%$ and $70 \%)$ aiming to study transitional flow using a combination of PIV and proper orthogonal decomposition (POD), and also proposed two complementary metrics for quantifying the levels of transitional flow: the energy decay slope and the entropy values [82]. Through POD analysis, they detected the transition to a more complex flow in both $50 \%$ and $70 \%$ stenotic models, while in the healthy model, no evidence of transitional flow was observed. In addition, the bigger complexity of flow in the $70 \%$ model was expressed by the flatter slope of energy decay and the higher entropy values when compared with those in the $50 \%$ stenotic model. Despite the interesting results obtained in this study, it is important to note that it may be necessary to acquire better resolution than the indicated by the standard POD convergence test in order to ensure adequate temporal resolution for turbulence quantification based on POD-derived parameters. Then, in another study [115], Kefayati et al. investigated not only the effect of stenosis severity $(30 \%, 50 \%$, and $70 \%)$ in carotid artery biomodels but also the plaque eccentricity (concentric or eccentric stenosis) and ulceration, taking into account its influence on the level of turbulence intensity (TI). The results obtained showed that, by increasing the stenosis severity, the turbulence intensity also increases. Furthermore, the authors observed that independently of stenosis severity, eccentricity caused more elevations in turbulence intensity over the concentric plaque model. Regarding the ulceration, they have observed that the $50 \%$ eccentric plaque produced a larger portion of moderate turbulence intensity when compared to the non-ulcerated model, mainly in the post-stenotic region. In general, this study proved that beyond the stenosis severity, other parameters can cause flow disturbances, like plaque eccentricity and ulceration. These factors enhance the turbulence downstream of stenosis, which, in turn, can have potential clinical implications, such as a stroke. Similarly, in another work [116], the authors also investigated the effect of the last features (stenosis severity, plaque eccentricity, and ulceration) on the levels and patterns of shear stress, derived from both laminar and turbulent phases, in the same biomodels. They observed that by increasing the stenosis severity, the level of laminar shear stress also increases, for both free shear stress (FSS) and wall shear stress (WSS). However, WSS increased twice. Independent of stenosis severity, the authors observed notable differences in the distribution and amount of shear stress indices between the concentric and eccentric plaque formations. In the eccentric model, the decay of the maximum WSS found at the stenosis throat was significantly steeper along the outer wall of the eccentric model when compared to the concentric counterpart. Compared to the non-ulcerated model counterpart model, the presence of ulceration in the $50 \%$ eccentric plaque model led to more elevated FSS and WSS levels. Concerning the turbulent (Reynolds) shear stress, elevated and dispersed levels were observed in the poststenotic recirculation zone of the eccentric stenotic model, becoming notable during the systolic deceleration phase, which was associated with jet instabilities. The combination of these three studies $[82,115,116]$ and their results revealed that beyond stenosis severity, other parameters can be used for a more sensitive assessment of stroke risk since they have the potential to promote serious clinical implications. In these studies, the biomodels were manufactured using a lost-core casting technique. A low melting point metal (LMPM) core in the shape of the desired lumen model geometry was cast from an aluminum mold. The core was mounted inside a plastic box and a second material, either plastic resin or agar gel, was then poured into the plastic box around the LMPM core. Once the material surrounding the core had solidified, the LMPM core was melted out. This manufacturing process was also used by other authors like DiCarlo et al. and Poepping et al. [105, 117 119]. Although this fabrication method has been applied by several authors, this method is not the most adequate as the presence of residues resulting from the process may compromise the flow visualization.

In addition to the previous investigations, Choi et al. [15] conducted another important in vitro study, where a comparison of rigid and deformable eccentric carotid stenosis was performed by applying a PIV method. A deformable stenosis model was fabricated by means of 3D printing (FDM) and investigated the stenosis deformation, since in a real situation, under a pulsatile blood flow condition, this phenomenon occurs. To mimic the thin fibrous cap, PDMS was wisely obtained by controlling the mixing ratio of the base and curing agent, curing temperature, and baking time to obtain a specific Young's modulus, and the oily phase of the lipid core part was obtained by using the liquid state of the Sylgard 184 base. After obtaining the physical models, the effect of the stenotic deformation on the pulsating waveform associated with the pressure drop by means of the turbulent kinetic energy (TKE) production rate was studied. The authors observed that the deformable stenosis model changes its stenotic shape to 
achieve high slope and height, when the inlet flow was changed. This shape variation causes an increase of the rate of the jet velocity, and as a result, promotes an increase of the TKE production rate, when compared with the rigid stenosis models. Due to this phenomenon, a phase delay of the peak position in the waveform related with the pressure drop across the stenosis was obtained. These results have revealed the viability of using the pressure drop waveform across the stenosis to detect deformable vulnerable stenosis.

\subsection{Generalized Models and Other Arteries}

Griffith et al. [120] applied a pulsatile inlet flow through a circular tube with an axisymmetric blockage and they have studied the effect of different degrees of stenosis in the flow behavior and stability both numerically and experimentally, by using an acrylic tube and PIV. For low Reynolds numbers, they observed a vortex ring downstream of the stenosis, in which strength and propagation velocity varied with the stenosis degree. In addition, the authors analyzed the linear stability and verified that experimental flows are less stable than the numerical analysis prediction. Despite those conclusions, it should be noted that the authors used water as a blood analogue, which has properties quite different from real blood and, thus, can present a different behavior.

From a different perspective, Helgeson et al. [101] showed a different example of the importance of combining in silico and in vitro studies by means of scanning electron microscopy (SEM) characterization. They fabricated a glass branched artery stenotic model mimicking the popliteal and femoral artery and investigated the transport of particles resulted from the orbital atherectomy technique. This methodology is widely used to treat atherosclerosis by debulking plaques from the arterial walls by applying a sanding action. The authors observed that there was no agglomeration of the plaque-replica particles and the accumulation only occurred under particular conditions. They also observed that the particles preferably tend to travel through upstream branches rather than downstream to the near-foot branches. From these results, new outcomes are expected to help the development of new atherectomy devices, and they can also be used to predict the endpoint of particles that are formed during this procedure.

\subsection{Final Remarks}

As can be seen, there are many different types of research, all of them with the same purpose, i.e., to understand the pathology of atherosclerosis. Thus, the research in this field can take many different directions and more studies are needed. Although there is a wide variety of research works on studying the flow in stenotic arteries, an effective method to manufacture in vitro biomodels has not yet been developed. Though, it was observed that $3 \mathrm{D}$ printing has become the preferred low-cost technology to obtain in vitro biomodels and, among the several methods, the SLA technique showed to be an accurate and powerful option, as long as adequate materials are employed [121]. This technique allowed to obtain biomodels with the lowest roughness providing the best quality for flow visualizations. It was also observed that the method to remove the lost core can interfere in the quality of the final biomodel, i.e., the lost core removed by heating processes will originate biomodels with the worst transparency. For the flow measurement in experimental tests, the $\mu$ PIV and PTV techniques showed a good agreement with the numerical studies, being adequate for their validation.

\section{BLOOD ANALOGUES}

The development of blood analog fluids to perform in vitro hemodynamic experiments is extremely relevant due to ethical, economic and safety problems related to the use of real blood in those experiments. Hence, several researchers have been focused on the development of new analogues in order to mimic not only the physical properties but also the flow behavior of the real blood, especially under steady shear conditions [122 - 128]. Some examples of those investigations are presented in Table $\mathbf{3}$.

Initially, the blood flow studies were performed with Newtonian blood analogues composed of mixtures of glycerol and water [129 - 134]. In a second stage, non-Newtonian fluids composed of xanthan gum (XG) or/and polyacrylamide (PAA) diluted in glycerin and/or water were developed and they have been applied in different studies, together with the Newtonian analogues [122, 135, 136].

Pinto et al. [36] found a noticeable cell-free layer around walls, when performing in vitro experiments with blood samples. The layer formation is due to the red blood cells (RBCs) migration to the center of the channel, which, in turn, leads to the reduction of the effective viscosity [137 - 142]. This physiological phenomenon does not happen with blood analogues fluids without solid elements, such as microparticles and microcapsules. Consequently, it is crucial to take into account the cellular blood components that exist within the base fluid [36, 143 - 145]. In addition, Lima and co-workers $[144,145]$ visualized and measured cell-cell interactions. They showed that the RBCs radial dispersion tends to increase with cell concentration and may influence the blood mass transport mechanisms. Hence, it is important that the hemodynamic flow phenomena that occur at the microscale level are also mimicked by particulate blood analogue fluids. RBCs are able to perform fundamental functions, such as the transport of gases and nutrients, but they also have the ability to deform under shear flow when they pass through a narrower capillary. Several experimental works [126, 146 - 149] developed blood analogue fluids containing polystyrene and polymethylmethacrylate (PMMA) particles to mimic the key structural attributes of RBCs. Despite the similar size and shape, the mechanical properties, i.e., the stiffness and deformability, were not identical to the real RBCs.

Subsequently, several types of particles with varying stiffness and shapes have been developed and their deformability in narrow channels was investigated [138, 146, 150 - 153]. Maruyama et al. [124, 154] developed a blood analogue made of a Newtonian solvent containing a suspension of microcapsules to evaluate the absolute hemolytic properties of centrifugal blood pumps. Later, Nguyen et al. [155] performed a similar study, but this time using a non-Newtonian solvent. The studies of the two aforementioned authors were performed with particulate blood analogues that are able to reproduce well the steady viscosity, but they did not study any 

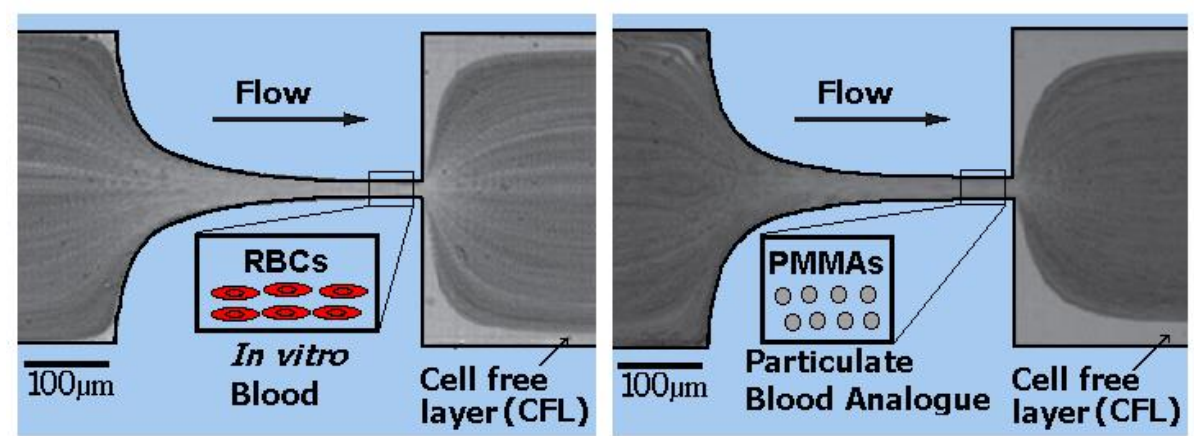

Fig. (5). Flow of in vitro blood and a particulate blood analogue (PMMA particles in Dx40) through hyperbolic contraction (adapted from [126]).

microscale flow phenomenon. An innovative blood analogue fluid containing giant unilamellar vesicles (GUVs) [156, 157] was developed to mimic the flow of RBCs in microchannels. The GUVs were made of a hydrated mixture of soybean lecithin, extruded through polycarbonate membranes, to guarantee the diameter of a uniform vesicle. Merkel et al. [158] synthesized hydrogel microparticles with tunable elasticity. They also evaluated the behavior of healthy and diseased RBCs and synthetic mimics of RBCs by using microfluidic models of vascular constriction. Vilanova et al. [159] successfully produced monodisperse silicon droplets to be used as templates for the formation of capsules with potential for molecular delivery with controlled release. The mechanical behavior of the generated capsules could be finely tuned by varying the geometrical parameters. Cui et al. [151] engineered polyethylene glycol hydrogel particles with adjustable elasticity and with a size similar to human RBCs. By using atomic force microscopy and a microfluidic blood capillary model that mimics dimensions and pressure differentials of the in vivo environment, they investigated the deformability behavior of these particles and demonstrated that this behavior could be tuned to be similar to that of RBCs. Choi et al. [160] developed a simple and fast method to produce micro-sized spherical PDMS particles by mixing uncured PDMS with distilled water.

Pinho et al. [149] and Calejo et al. [126] developed particulate blood analogues with rigid particles able to show a cell-free layer formation downstream of a microchannel contraction and the reproduction of the viscosity curve of rigid RBCs suspensions. In Fig. (5), the comparison between the flow of RBCs and PMMA is illustrated. However, both studies suggested that the only way to closely mimic some microscale blood-flow phenomena is by using deformable microparticles. Recently, Muñoz-Sánchez et al. [127, 161] proposed a flowfocusing technique to produce micro-sized PDMS flexible spherical particles for biomicrofluidic applications, also demonstrating the ability of the proposed particulate fluid to reproduce the steady shear viscosity curve of ovine RBCs suspended in Dextran 40. More recently, Lima et al. [162] proposed a simple, low cost and stable multiphase blood analogue with the ability to mimic microscale blood flow phenomena. The proposed analogue is composed of Brij L4 surfactant micelles suspended in pure water and has a great potential to be used in flow experiments from macro to nanoscale levels.

The development of fluids with microparticles that mimic the behavior of RBCs is still an ongoing challenge for the scientific community. Nevertheless, the analogues used in recent studies have already contributed to improve our understanding of several relevant hemodynamic phenomena and develop biomedical microdevices. The majority of the particles are made by polymeric or lipidic flexible materials due to their similar mechanical properties when compared with the RBCs. However, there are still several critical challenges that need to be solved such as the mass production of flexible microparticles, aggregation and fast agglomeration of the microparticles within the microchannels.

\section{CONCLUSION AND FUTURE DIRECTIONS}

Atherosclerosis is the primary cause of morbidity and mortality worldwide, having a great negative impact on society around the world. The breakthrough in 3D printing technologies has enabled the production of stenotic arterial biomodels, both idealized and patient-specific, directly from CAD data. These arterial biomodels are remarkably important due to the ability to validate numerical results and to deeply study atherosclerosis pathology and its effect on hemodynamics. There are several methodologies to produce and perform in vitro experiments, making it extremely complex to suggest which is the optimal process. Moreover, there are some drawbacks, limiting the applicability of the outcomes for clinical practice. For instance, assumptions regarding flow behavior, stiffness of the wall, simplified blood analogues and inaccurate vessel geometries are properties that can affect the clinical value of many findings.

This paper provides a review of different kinds of in vitro studies focusing on stenotic artery biomodels. In addition, it shows different $3 \mathrm{D}$ printing techniques able to produce stenotic biomodels and the importance of the blood analogue fluids to perform flow visualizations. The most cost-effective techniques currently used are the laser type, SLA, the jetting type, and FDM. The most common material used to perform in vitro flow studies is PDMS, not only due to its low-cost, biocompatibility, and optical transparency but also due to its elasticity. The most reported measuring techniques were PIV 
and $\mu$ PIV. These techniques lead to the generation of accurate flow velocity profiles. Also, while the other techniques measure the velocity at a point, PIV measurements produce two-dimensional or even three-dimensional vector fields. Regarding the blood analogue fluids, still, most of the fluids are water-based or they are made with a mixture of water and glycerin or glycerol. However, most of the recent analogue fluids have the ability to replicate the non-Newtonian behavior of the blood, while others have flexible microparticles to simulate the mechanical behavior of the RBCs.

This review also shows that the current state-of-the-art biomodel in stenotic arteries is capable of interpreting and mimicking hemodynamic dysfunction and it can be used to optimize the existing treatments and to enhance the medical management of the atherosclerotic disease. Investigation in fluid mechanics has a relevant contribution to the design of interventional diagnostic, measuring, and treatment devices. Further research is needed to better understand the physiological phenomena that occur in pathological conditions. For instance, the properties of atherosclerotic plaque are most likely to be very heterogeneous, anisotropic, and non-linear.

\section{CONSENT FOR PUBLICATION}

Not applicable.

\section{FUNDING}

This work has been supported by FCT - Fundação para a Ciência e Tecnologia within the R\&D Units Project Scope: UIDB/00319/2020, UIDB/04077/2020, UIDB/00690/2020, UIDB/04436/2020 and NORTE-01-0145-FEDER-030171, NORTE-01-0145-FEDER-029394 funded by COMPETE2020, NORTE 2020, PORTUGAL 2020, Lisb@2020 and FEDER.

\section{CONFLICT OF INTEREST}

Pedro F. Costa is CEO \& CTO and shareholder of the company Biofabics Lda.

\section{ACKNOWLEDGEMENTS}

The authors acknowledge funding support by FCT Fundação para a Ciência e Tecnologia.

\section{REFERENCES}

[1] World Health Organization (WHO), Cardiovasc. Dis. Fact Sheet No. 317, 2017.

[2] Y. Huo, M. Svendsen, J.S. Choy, Z.D. Zhang, and G.S. Kassab, "A validated predictive model of coronary fractional flow reserve", $J$. $R$. Soc. Interface, vol. 9, no. 71, pp. 1325-1338, 2012 [http://dx.doi.org/10.1098/rsif.2011.0605] [PMID: 22112650]

[3] D. Pinho, D. Bento, J. Ribeiro, R. Lima, and M. Vaz, An In Vitro Experimental Evaluation of the Displacement Field in an Intracranial Aneurysm Model.New Trends Mech. Mach. Sci., Springer, 2015, pp. 261-268.

[http://dx.doi.org/10.1007/978-3-319-09411-3_28]

[4] M. Minakawa, I. Fukuda, T. Igarashi, K. Fukui, H. Yanaoka, and T. Inamura, "Hydrodynamics of aortic cannulae during extracorporeal circulation in a mock aortic arch aneurysm model", Artif. Organs, vol. 34, no. 2, pp. 105-112, 2010.

[http://dx.doi.org/10.1111/j.1525-1594.2009.00764.x] [PMID: 19995359]

[5] R.O. Rodrigues, D. Pinho, D. Bento, R. Lima, and J. Ribeiro, "Wall expansion assessment of an intracranial aneurysm model by a $3 \mathrm{D}$ digital image correlation system", Measurement, vol. 88, pp. 262-270,
2016.

[http://dx.doi.org/10.1016/j.measurement.2016.03.045]

[6] Y. Shimizu, A. Javadzadegan, T. Hayase, and M. Ohta, "Flow observations in elastic stenosis biomodel with comparison to rigid-like model", Technol. Health Care, vol. 21, no. 4, pp. 305-314, 2013. [http://dx.doi.org/10.3233/THC-130725] [PMID: 23949173]

[7] H. Thomas, J. Diamond, A. Vieco, S. Chaudhuri, E. Shinnar, S. Cromer, P. Perel, G.A. Mensah, J. Narula, C.O. Johnson, G.A. Roth, and A.E. Moran, Global Atlas of Cardiovascular Disease Prevention and Control., World Health Organization, 2011.

[8] Y. Sun, and X. Guan, "Autophagy: A new target for the treatment of atherosclerosis", Front. Lab. Med., vol. 2, pp. 68-71, 2018. [http://dx.doi.org/10.1016/j.flm.2018.07.002]

[9] A.J. Apostolidis, A.N. Beris, and P.S. Dhurjati, "Introducing CFD through a cardiovascular application in a fluid mechanics course", Chem. Eng. Educ., vol. 48, pp. 175-184, 2014.

[10] T. Wang, "Pathogenesis of atherosclerosis", Diagn. Histopathol., vol 23, pp. 473-478, 2017.

[http://dx.doi.org/10.1016/j.mpdhp.2017.11.009]

[11] P. Libby, J.E. Buring, L. Badimon, G.K. Hansson, J. Deanfield, M.S Bittencourt, L. Tokgözoğlu, and E.F. Lewis, "Atherosclerosis", Nat. Rev. Dis. Primers, vol. 5, no. 1, p. 56, 2019.

[http://dx.doi.org/10.1038/s41572-019-0106-z] [PMID: 31420554]

[12] C. VanPutte, J. Regan, A. Russo, B. Manager, and A. Reed, Seeley's Essentials of Anatomy \& physiology., Ninth, McGraw-Hill Education, 2016.

[13] A. Saxena, E.Y.K. Ng, and S.T. Lim, "Imaging modalities to diagnose carotid artery stenosis: progress and prospect", Biomed. Eng. Online, vol. 18 , no. 1 , p. 66,2019 .

[http://dx.doi.org/10.1186/s12938-019-0685-7] [PMID: 31138235]

[14] C. Moreno, and K. Bhaganagar, "Modeling of stenotic coronary artery and implications of plaque morphology on blood flow", Model. Simul. Eng., vol. 2013, pp. 1-14, 2013. [http://dx.doi.org/10.1155/2013/390213]

[15] W. Choi, J.H. Park, H. Byeon, and S.J. Lee, "Flow characteristics around a deformable stenosis under pulsatile flow condition", Phys. Fluids, vol. 30, pp. 1070-6631, 2018.

[http://dx.doi.org/10.1063/1.5009063]

[16] R.K. Banerjee, K.D. Ashtekar, T.A. Helmy, M.A. Effat, L.H. Back, and S.F. Khoury, "Hemodynamic diagnostics of epicardial coronary stenoses: in-vitro experimental and computational study", Biomed. Eng. Online, vol. 7, p. 24, 2008

[http://dx.doi.org/10.1186/1475-925X-7-24] [PMID: 18752683]

[17] S.C.P. Cheung, K.K.L. Wong, G.H. Yeoh, W. Yang, J. Tu, R. Beare, and T. Phan, "Experimental and numerical study on the hemodynamics of stenosed carotid bifurcation", Australas. Phys. Eng. Sci. Med., vol. 33, no. 4, pp. 319-328, 2010.

[http://dx.doi.org/10.1007/s13246-010-0050-4] [PMID: 21203880]

[18] J. Bale-Glickman, K. Selby, D. Saloner, and O. Savas, "Experimental flow studies in exact-replica phantoms of atherosclerotic carotid bifurcations under steady input conditions", J. Biomech. Eng., vol. 125, no. 1, pp. 38-48, 2003.

[http://dx.doi.org/10.1115/1.1537734] [PMID: 12661195]

[19] A. Karimi, M. Navidbakhsh, A. Shojaei, K. Hassani, and S. Faghihi, "Study of plaque vulnerability in coronary artery using Mooney-Rivlin model: A combination of finite element and experimental method", Biomed. Eng. Appl. Basis Commun., vol. 26, pp. 1-7, 2014. [http://dx.doi.org/10.4015/S1016237214500136]

[20] A. Karimi, and R. Razaghi, "Interaction of the blood components and plaque in a stenotic coronary artery", Artery Res., vol. 24, pp. 47-61, 2018.

[http://dx.doi.org/10.1016/j.artres.2018.11.002]

[21] N. DePaola, M.A. Gimbrone Jr, P.F. Davies, and C.F. Dewey Jr, "Vascular endothelium responds to fluid shear stress gradients", Arterioscler. Thromb., vol. 12, no. 11, pp. 1254-1257, 1992. [http://dx.doi.org/10.1161/01.ATV.12.11.1254] [PMID: 1420084]

[22] A.V. Dokunin, "A modification of the method of differential manometry for registration of the volume velocity of the blood flow", Bull. Exp. Biol. Med., vol. 46, pp. 1414-1417, 1958.

[http://dx.doi.org/10.1007/BF00845194]

[23] K. Stepniak, A. Ursani, N. Paul, and H. Naguib, "Development of a phantom network for optimization of coronary artery disease imaging using computed tomography", Biomed. Phys. Eng. Express, vol. 5, p. 45019, 2019

[http://dx.doi.org/10.1088/2057-1976/ab2696]

[24] P.J. Brands, A.P.G. Hoeks, L. Hofstra, and R.S. Reneman, "A noninvasive method to estimate wall shear rate using ultrasound", 
Ultrasound Med. Biol., vol. 21, no. 2, pp. 171-185, 1995. [http://dx.doi.org/10.1016/S0301-5629(94)00111-1] [PMID: 7571127]

[25] B. Dunmire, K.W. Beach, K. Labs, M. Plett, and D.E. Strandness Jr, "Cross-beam vector Doppler ultrasound for angle-independent velocity measurements", Ultrasound Med. Biol., vol. 26, no. 8, pp. 1213-1235, 2000.

[http://dx.doi.org/10.1016/S0301-5629(00)00287-8]

[PMID: 11120358]

[26] S. Sjostrand, A. Widerstrom, A.R. Ahlgren, and M. Cinthio, "Design and fabrication of a conceptual arterial ultrasound phantom capable of exhibiting longitudinal wall movement", IEEE Trans. Ultrason. Ferroelectr. Freq. Control, vol. 64, no. 1, pp. 11-18, 2017. [http://dx.doi.org/10.1109/TUFFC.2016.2597246] [PMID: 27529873]

[27] P. Papathanasopoulou, S. Zhao, U. Köhler, M.B. Robertson, Q. Long, P. Hoskins, X.Y. Xu, and I. Marshall, "MRI measurement of timeresolved wall shear stress vectors in a carotid bifurcation model, and comparison with CFD predictions", J. Magn. Reson. Imaging, vol. 17, no. 2 , pp. $153-162,2003$ [http://dx.doi.org/10.1002/jmri.10243] [PMID: 12541221]

[28] R.S. Reneman, T. Arts, and A.P.G. Hoeks, "Wall shear stress--an important determinant of endothelial cell function and structure-in the arterial system in vivo. Discrepancies with theory", J. Vasc. Res., vol. 43, no. 3, pp. 251-269, 2006.

[http://dx.doi.org/10.1159/000091648] [PMID: 16491020]

[29] Y. Karnam, Multiscale Fluid-Structure Interaction Models Development and Applications to the $3 D$ Elements of a Human Cardiovascular System Multiscale Fluid-Structure Interaction Models, Kate Gleason College of Engineering Department., Rochester Institute of Technology Kate, 2019.

[30] M.H. Friedman, and D.P. Giddens, "Blood flow in major blood vessels-modeling and experiments", Ann. Biomed. Eng., vol. 33, no. 12, pp. 1710-1713, 2005

[http://dx.doi.org/10.1007/s10439-005-8773-1] [PMID: 16389517]

[31] B. Chayer, and M. Hoven, "Cardinal, Marie-Hèlène, L. Hongliang, R. Lopata, G. Cloutier, Atherosclerotic carotid bifurcation phantoms with stenotic soft inclusion for ultrasound flow and vessel wall elastography imaging", Phys. Med. Biol., vol. 64, p. 95025, 2019.

[http://dx.doi.org/10.1088/1361-6560/ab1145]

[32] G. Goudot, J. Poree, O. Pedreira, L. Khider, P. Julia, J.M. Alsac, E. Laborie, T. Mirault, M. Tanter, E. Messas, and M. Pernot, "Wall Shear Stress Measurement by Ultrafast Vector Flow Imaging for Atherosclerotic Carotid Stenosis", Ultraschall Med., p. 40, 2019. [http://dx.doi.org/10.1055/a-1060-0529] [PMID: 31856281]

[33] L. Queijo, and R. Lima, PDMS Anatomical Realistic Models for Hemodynamic Studies Using Rapid Prototyping Technology.Int. Fed. Med. Biol. Eng., Springer: Germany, 2010, pp. 434-437.

[http://dx.doi.org/10.1007/978-3-642-14515-5_111]

[34] A. Souza, M.S. Souza, D. Pinho, R. Agujetas, C. Ferrera, R. Lima, H. Puga, and J. Ribeiro, 3D manufacturing of intracranial aneurysm biomodels for flow visualizations: Low cost fabrication processes.Mechanics Research Communications., vol. 107, -1035352020 .

[http://dx.doi.org/10.1016/j.mechrescom.2020.103535]

[35] S. Einav, H.J. Berman, R.L. Fuhro, P.R. DiGiovanni, S. Fine, and J.D. Fridman, "Measurement of velocity profiles of red blood cells in the microcirculation by laser doppler anemometry (LDA)", Biorheology, vol. 12 , no. $3-4$, pp. $207-210,1975$

[http://dx.doi.org/10.3233/BIR-1975-123-411] [PMID: 1203523]

[36] E. Pinto, V. Faustino, R.O. Rodrigues, D. Pinho, V. Garcia, J.M. Miranda, and R. Lima, "A Rapid and Low-Cost Nonlithographic Method to Fabricate Biomedical Microdevices for Blood Flow Analysis", Micromachines, pp. 121-135, 2015. [http://dx.doi.org/10.3390/mi6010121]

[37] F. Kabinejadian, D.N. Ghista, B. Su, M.K. Nezhadian, L.P. Chua, J.H. Yeo, and H.L. Leo, "In vitro measurements of velocity and wall shear stress in a novel sequential anastomotic graft design model under pulsatile flow conditions", Med. Eng. Phys., vol. 36, no. 10, pp. 1233-1245, 2014.

[http://dx.doi.org/10.1016/j.medengphy.2014.06.024]

[PMID: 25103345]

[38] R.L. Hewlin Jr, and J.P. Kizito, "Development of an experimental and digital cardiovascular arterial model for transient hemodynamic and postural change studies: "A preliminary framework analysis"", Cardiovasc. Eng. Technol., vol. 9, no. 1, pp. 1-31, 2018. [http://dx.doi.org/10.1007/s13239-017-0332-z] [PMID: 29124548]

[39] S.M. Park, Y.U. Min, M.J. Kang, K.C. Kim, and H.S. Ji, "In vitro hemodynamic study on the stenotic right coronary artery using experimental and numerical analysis", J. Mech. Med. Biol., vol. 10, pp. 695-712, 2010.

[http://dx.doi.org/10.1142/S0219519410003812]

[40] D.J. Ravnic, Y.Z. Zhang, A. Tsuda, J.P. Pratt, H.T. Huss, and S.J. Mentzer, "Multi-image particle tracking velocimetry of the microcirculation using fluorescent nanoparticles", Microvasc. Res., vol. 72, no. 1-2, pp. 27-33, 2006.

[http://dx.doi.org/10.1016/j.mvr.2006.04.006] [PMID: 16806290]

[41] M. Büsen, T.A.S. Kaufmann, M. Neidlin, U. Steinseifer, and S.J. Sonntag, "In vitro flow investigations in the aortic arch during cardiopulmonary bypass with stereo-PIV", J. Biomech., vol. 48, no. 10, pp. 2005-2011, 2015.

[http://dx.doi.org/10.1016/j.jbiomech.2015.03.030] [PMID: 25907548]

[42] A. Rezvan, C.W. Ni, N. Alberts-Grill, and H. Jo, "Animal, In vitro, and ex vivo models of flow-dependent atherosclerosis: Role of oxidative stress", Antioxid. Redox Signal., vol. 15, no. 5, pp. 1433-1448, 2011

[http://dx.doi.org/10.1089/ars.2010.3365] [PMID: 20712399]

[43] M. Dusinska, E. Rundén-Pran, S.C. Carreira, and M. Saunders, "Critical Evaluation of Toxicity Tests", Advers. Eff. Eng. Nanomater, pp. 63-83, 2012.

[44] W.P. Santamore, P. Walinsky, A.A. Bove, R.H. Cox, R.A. Carey, and J.F. Spann, "The effects of vasoconstriction on experimental coronary artery stenosis", Am. Heart J., vol. 100, no. 6 Pt 1, pp. 852-858, 1980. [http://dx.doi.org/10.1016/0002-8703(80)90066-6] [PMID: 7446388]

[45] W. Versteeg, H K; Malalasekera, An Introduction to Computational Fluid Dynamics, The finite volume method, Second., Prentice Hall, 2007.

[46] R. Agujetas, M.R. González-Fernández, J.M. Nogales-Asensio, and J.M. Montanero, "Numerical analysis of the pressure drop across highly-eccentric coronary stenoses: Application to the calculation of the fractional flow reserve", Biomed. Eng. Online, vol. 17, no. 1, p. 67, 2018 .

[http://dx.doi.org/10.1186/s12938-018-0503-7] [PMID: 29848333]

[47] Y. Imai, T. Omori, Y. Shimogonya, T. Yamaguchi, and T. Ishikawa, "Numerical methods for simulating blood flow at macro, micro, and multi scales", J. Biomech., vol. 49, no. 11, pp. 2221-2228, 2016.

[http://dx.doi.org/10.1016/j.jbiomech.2015.11.047] [PMID: 26705108]

[48] X. Ge, Y. Liu, Z. Yin, S. Tu, Y. Fan, Y. Vassilevski, S. Simakov, and F. Liang, "Comparison of Instantaneous Wave-Free Ratio (iFR) and Fractional Flow Reserve (FFR) with respect to their sensitivities to cardiovascular factors: A computational model-based study", J. Interv. Cardiol., vol. 2020, p. 4094121, 2020.

[http://dx.doi.org/10.1155/2020/4094121] [PMID: 32508540]

[49] V. Carvalho, N. Rodrigues, R. Ribeiro, P. Costa, J.C.F. Teixeira, R. Lima, and S.F.C.F. Teixeira, "Hemodynamic study in 3D printed stenotic coronary artery models: Experimental validation and transient simulation", Comput. Methods Biomech. Biomed. Eng., 2020. [http://dx.doi.org/10.1080/10255842.2020.1842377]

[50] V. Carvalho, N. Rodrigues, R.A. Lima, and S. Teixeira, "Numerical simulation of blood pulsatile flow in stenotic coronary arteries: The effect of turbulence modeling and non-Newtonian assumptions", Int. Conf. Appl. Math. Comput. Sci., , 2020

[51] I. Sazonov, A.W. Khir, W.S. Hacham, E. Boileau, J.M. Carson, R. van Loon, C. Ferguson, and P. Nithiarasu, "A novel method for noninvasively detecting the severity and location of aortic aneurysms", Biomech. Model. Mechanobiol., vol. 16, no. 4, pp. 1225-1242, 2017. [http://dx.doi.org/10.1007/s10237-017-0884-8] [PMID: 28220320]

[52] T.M. Gamilov, F.Y. Liang, and S.S. Simakov, "Mathematical Modeling of the Coronary Circulation During Cardiac Pacing and Tachycardia", Lobachevskii J. Math., vol. 40, pp. 448-458, 2019. [http://dx.doi.org/10.1134/S1995080219040073]

[53] Y.V. Vassilevski, V.Y. Salamatova, and S.S. Simakov, "On the elasticity of blood vessels in one-dimensional problems of hemodynamics", Comput. Math. Math. Phys., vol. 55, pp. 1567-1578, 2015.

[http://dx.doi.org/10.1134/S0965542515090134]

[54] N.M. Maurits, G.E. Loots, and A.E.P. Veldman, "The influence of vessel wall elasticity and peripheral resistance on the carotid artery flow wave form: a CFD model compared to in vivo ultrasound measurements", J. Biomech., vol. 40, no. 2, pp. 427-436, 2007. [http://dx.doi.org/10.1016/j.jbiomech.2005.12.008] [PMID: 16464454]

[55] M. Ahmadi, and R. Ansari, "Computational simulation of an artery narrowed by plaque using 3D FSI method: Influence of the plaque angle, non-Newtonian properties of the blood flow and the hyperelastic artery models", Biomed. Phys. Eng. Express, vol. 5, p. 45037, 2019 
[http://dx.doi.org/10.1088/2057-1976/ab323f]

[56] T. Canchi, A. Saxena, E. Ng, E.C. Pwee, and S. Narayanan, "Application of fluid-structure interaction methods to estimate the mechanics of rupture in asian abdominal aortic aneurysms", Bionanoscience, vol. 8, pp. 1035-1044, 2018.

[http://dx.doi.org/10.1007/s12668-018-0554-z]

[57] T. Canchi, E.Y.K. Ng, A. Saxena, and S. Narayanan, CFD-Based Postprocessing of CT-MRI Data to Determine the Mechanics of Rupture in Abdominal Aortic Aneurysms Multi-Modality Imaging, Springer, Cham, 2018.

[http://dx.doi.org/10.1007/978-3-319-98974-7 4]

[58] D. Lopes, H. Puga, J.C. Teixeira, and S.F. Teixeira, "Influence of arterial mechanical properties on carotid blood flow: Comparison of CFD and FSI studies", Int. J. Mech. Sci., vol. 160, pp. 209-218, 2019. [http://dx.doi.org/10.1016/j.ijmecsci.2019.06.029]

[59] M. Malvè, A. García, J. Ohayon, and M.A. Martínez, "Unsteady blood flow and mass transfer of a human left coronary artery bifurcation: FSI vs. CFD", Int. Commun. Heat Mass Transf., vol. 39, pp. 745-751, 2012.

[http://dx.doi.org/10.1016/j.icheatmasstransfer.2012.04.009]

[60] A. Saxena, V. Saha, and E.Y.K. Ng, "Skin temperature maps as a measure of carotid artery stenosis", Comput. Biol. Med., vol. 116, p. 103548,2020

[http://dx.doi.org/10.1016/j.compbiomed.2019.103548] [PMID: 31760270]

[61] B.B. Lieber, M. Siebes, and T. Yamaguchi, "Correlation of hemodynamic events with clinical and pathological observations", Ann. Biomed. Eng., vol. 33, no. 12, pp. 1695-1703, 2005.

[http://dx.doi.org/10.1007/s10439-005-8760-6] [PMID: 16389515]

[62] E. Doutel, J. Carneiro, J.B.L.M. Campos, and J.M. Miranda, "Experimental and numerical methodology to analyze flows in a coronary bifurcation", Eur. J. Mech. BFluids, vol. 67, pp. 341-356, 2018.

[http://dx.doi.org/10.1016/j.euromechflu.2017.09.009]

[63] V. Carvalho, N. Rodrigues, R. Ribeiro, P.F. Costa, R.A. Lima, and SFCF. Teixeira, "3D printed biomodels for flow visualization in stenotic vessels: An experimental and numerical study", Micromachines, vol. 11, no. 6, p. 549, 2020.

[64] E. Boileau, P. Nithiarasu, P.J. Blanco, L.O. Müller, F.E. Fossan, L.R. Hellevik, W.P. Donders, W. Huberts, M. Willemet, and J. Alastruey, "A benchmark study of numerical schemes for one-dimensional arterial blood flow modelling", Int. J. Numer. Methods Biomed. Eng., vol. 31 , no. 10,2015 .

[http://dx.doi.org/10.1002/cnm.2732] [PMID: 26100764]

[65] J. Alastruey, A.W. Khir, K.S. Matthys, P. Segers, S.J. Sherwin, P.R. Verdonck, K.H. Parker, and J. Peiró, "Pulse wave propagation in a model human arterial network: Assessment of 1-D visco-elastic simulations against in vitro measurements", J. Biomech., vol. 44, no. 12, pp. 2250-2258, 2011

[http://dx.doi.org/10.1016/j.jbiomech.2011.05.041] [PMID: 21724188]

[66] N. Bessonov, A. Sequeira, S. Simakov, Y. Vassilevskii, and V. Volpert, "Methods of Blood Flow Modelling", Math. Model. Nat. Phenom., vol. 11, pp. 1-25, 2016.

[http://dx.doi.org/10.1051/mmnp/201611101]

[67] N. El Khatib, O. Kafi, A. Sequeira, S. Simakov, Y. Vassilevski, and V. Volpert, "Mathematical modelling of atherosclerosis", Math. Model. Nat. Phenom., vol. 14, pp. 1-25, 2019

[http://dx.doi.org/10.1051/mmnp/2019050]

[68] D. Katritsis, L. Kaiktsis, A. Chaniotis, J. Pantos, E.P. Efstathopoulos, and V. Marmarelis, "Wall shear stress: theoretical considerations and methods of measurement", Prog. Cardiovasc. Dis., vol. 49, no. 5, pp. 307-329, 2007.

[http://dx.doi.org/10.1016/j.pcad.2006.11.001] [PMID: 17329179]

[69] F. Rikhtegar, F. Pacheco, C. Wyss, K.S. Stok, H. Ge, and R.J. Choo,

[70] S.G. Yazdi, P.H. Geoghegan, P.D. Docherty, M. Jermy, and A. Khanafer, "A Review of Arterial Phantom Fabrication Methods for Flow Measurement Using PIV Techniques", Ann. Biomed. Eng., vol. 46, no. 11, pp. 1697-1721, 2018.

[http://dx.doi.org/10.1007/s10439-018-2085-8] [PMID: 29987543]

[71] E. Fröhlich, and S. Salar-behzadi, Toxicological Assessment of Inhaled Nanoparticles: Role of in Vivo, ex Vivo, in Vitro, and in Silico Studies, 2014, pp. 4795-4822.

[72] C.A.J. Fletcher, Computational Techniques for Fluid Dynamics., vol. 1. Second, Springer, 1991.

[http://dx.doi.org/10.1007/978-3-642-58239-4]

[73] T. Yamaguchi, T. Ishikawa, K. Tsubota, Y. Imai, M. Nakamura, and T. Fukui, "Computational blood flow analysis new trends and methods", J. Biomech. Sci. Eng., vol. 1, pp. 29-50, 2006

[http://dx.doi.org/10.1299/jbse.1.29]

[74] G. Biglino, P. Verschueren, R. Zegels, A.M. Taylor, and S. Schievano, "Rapid prototyping compliant arterial phantoms for in-vitro studies and device testing", J. Cardiovasc. Magn. Reson., vol. 15, p. 2, 2013. [http://dx.doi.org/10.1186/1532-429X-15-2] [PMID: 23324211]

[75] E. Doutel, N. Viriato, J. Carneiro, J.B.L.M. Campos, and J.M. Miranda, "Geometrical effects in the hemodynamics of stenotic and non-stenotic left coronary arteries-numerical and in vitro approaches", Int. J. Numer. Methods Biomed. Eng., vol. 35, no. 8, p. e3207, 2019. [http://dx.doi.org/10.1002/cnm.3207] [PMID: 30983149]

[76] R. Jewkes, H.E. Burton, and D.M. Espino, "Towards additive manufacture of functional, spline-based morphometric models of healthy and diseased coronary arteries: In vitro proof-of-concept using a porcine template", J. Funct. Biomater., vol. 9, no. 1, p. E15, 2018. [http://dx.doi.org/10.3390/jfb9010015] [PMID: 29393899]

[77] P.F. Costa, H.J. Albers, J.E.A. Linssen, H.H.T. Middelkamp, L. van der Hout, R. Passier, A. van den Berg, J. Malda, and A.D. van der Meer, "Mimicking arterial thrombosis in a 3D-printed microfluidic in vitro vascular model based on computed tomography angiography data", Lab Chip, vol. 17, no. 16, pp. 2785-2792, 2017. [http://dx.doi.org/10.1039/C7LC00202E] [PMID: 28717801]

[78] J.M. Zhang, L.P. Chua, D.N. Ghista, T.M. Zhou, and Y.S. Tan, "Validation of numerical simulation with PIV measurements for two anastomosis models", Med. Eng. Phys., vol. 30, no. 2, pp. 226-247, 2008.

[http://dx.doi.org/10.1016/j.medengphy.2007.02.004]

[PMID: 17466565]

[79] M. Sayed Razavi, and E. Shirani, "Development of a general method for designing microvascular networks using distribution of wall shear stress", J. Biomech., vol. 46, no. 13, pp. 2303-2309, 2013.

[http://dx.doi.org/10.1016/j.jbiomech.2013.06.005] [PMID: 23891174]

[80] J. Robert, B. Weber, L. Frese, M.Y. Emmert, D. Schmidt, A. von Eckardstein, L. Rohrer, and S.P. Hoerstrup, "A three-dimensional engineered artery model for in vitro atherosclerosis research", PLoS One, vol. 8, no. 11, p. e79821, 2013.

[http://dx.doi.org/10.1371/journal.pone.0079821] [PMID: 24244566]

[81] S.S. Mulani, and P.I. Jagad, "Analysis of the Effects of Plaque Deposits on the Blood Flow through Human Artery", Int. Eng. Res. J., vol. 41, pp. 2319-3182, 2015. Available at: http://www.irdindia.in/ journal_ijtarme/pdf/vol4_iss1/12.pdf

[82] S. Kefayati, and T.L. Poepping, "Transitional flow analysis in the carotid artery bifurcation by proper orthogonal decomposition and particle image velocimetry", Med. Eng. Phys., vol. 35, no. 7, pp. 898-909, 2013.

[http://dx.doi.org/10.1016/j.medengphy.2012.08.020]

[PMID: 23025907]

[83] E. Doutel, J. Carneiro, and M. Oliveira, "Fabrication of 3D milis-scale channels for hemodynamic studies", J. Mech. Med. Biol., vol. 12, pp. 367-374, 2015.

[http://dx.doi.org/10.1142/S0219519415500049]

[84] R. Naryan, Rapid Prototyping of Biomaterials., 1st ed Woodhead Publishing, Limited, 2014.

[85] D.M. Kalaskar, 3D Printing in Medicine, First., Elsevier, 2017.

[86] S.H. Huang, P. Liu, A. Mokasdar, and L. Hou, "Additive manufacturing and its societal impact: A literature review", Int. J. Adv. Manuf. Technol., vol. 67, pp. 1191-1203, 2013.

[http://dx.doi.org/10.1007/s00170-012-4558-5]

[87] X. Wang, Q. Ao, X. Tian, J. Fan, Y. Wei, W. Hou, H. Tong, and S. Bai, "S. Bai, 3D bioprinting technologies for hard tissue and organ engineering", Materials, vol. 9, no. 10, pp. 1-23, 2016. [http://dx.doi.org/10.3390/ma10010001] [PMID: 28773924]

[88] F.P.W. Melchels, J. Feijen, and D.W. Grijpma, "A review on stereolithography and its applications in biomedical engineering", Biomaterials, vol. 31, no. 24, pp. 6121-6130, 2010 . [http://dx.doi.org/10.1016/j.biomaterials.2010.04.050]

[PMID: 20478613]

[89] C.L. Faria, D. Pinho, J. Santos, and L.M. Gonçalves, "Low cost 3D printed biomodels for biofluid mechanics applications", J. Mech. Eng. Biomech., vol. 3, pp. 1-7, 2018.

[http://dx.doi.org/10.24243/JMEB/3.1.166]

[90] L. Hütter, P.H. Geoghegan, P.D. Docherty, M.S. Lazarjan, D. Clucas, and M. Jermy, "Fabrication of a compliant phantom of the human aortic arch for use in Particle Image Velocimetry (PIV) experimentation", Curr. Dir. Biomed. Eng., vol. 2, pp. 493-497, 2016. [http://dx.doi.org/10.1515/cdbme-2016-0109]

[91] B.K. Gu, D.J. Choi, S.J. Park, M.S. Kim, C.M. Kang, and C.H. Kim, 
"3-dimensional bioprinting for tissue engineering applications", Biomater. Res., vol. 20, p. 12, 2016

[http://dx.doi.org/10.1186/s40824-016-0058-2] [PMID: 27114828]

[92] K.I. Aycock, P. Hariharan, and B.A. Craven, "Particle image velocimetry measurements in an anatomical vascular model fabricated using inkjet 3D printing", Exp. Fluids, vol. 58, pp. 1-8, 2017. [http://dx.doi.org/10.1007/s00348-017-2403-1]

[93] J. Brunette, R. Mongrain, and J.C. Tardif, "A realistic coronary artery phantom for particle image velocimetry: Featuring injection-molded inclusions and multiple layers", J. Vis., vol. 7, pp. 241-248, 2004. [http://dx.doi.org/10.1007/BF03181639]

[94] D. Maragiannis, M.S. Jackson, S.R. Igo, R.C. Schutt, P. Connell, J. Grande-Allen, C.M. Barker, S.M. Chang, M.J. Reardon, W.A. Zoghbi, and S.H. Little, "Replicating Patient-Specific Severe Aortic Valve Stenosis With Functional 3D Modeling", Circ Cardiovasc Imaging, vol. 8 , no. 10 , p. e003626, 2015.

[http://dx.doi.org/10.1161/CIRCIMAGING.115.003626] [PMID: 26450122]

[95] K. Stepniak, A. Ursani, N. Paul, and H. Naguib, "Novel 3D printing technology for CT phantom coronary arteries with high geometrical accuracy for biomedical imaging applications", Bioprinting., vol. 18, p. e00074, 2020.

[http://dx.doi.org/10.1016/j.bprint.2020.e00074]

[96] A. Malone, D. Chari, S. Cournane, I. Naydenova, A. Fagan, and J. Browne, "Investigation of the assessment of low degree $(<50 \%)$ renal artery stenosis based on velocity flow profile analysis using Doppler ultrasound: An in-vitro study", Phys. Med., vol. 65, pp. 209-218, 2019. [http://dx.doi.org/10.1016/j.ejmp.2019.08.016] [PMID: 31518907]

[97] Y. Asaad, M. Epshtein, A. Yee, and N. Korin, "The Flow Dependent Adhesion of von Willebrand Factor (VWF)-A1 Functionalized Nanoparticles in an in Vitro Coronary Stenosis Model", Molecules, vol. 24 , no. 15 , p. $2679,2019$.

[http://dx.doi.org/10.3390/molecules24152679] [PMID: 31344782]

[98] P.H. Geoghegan, N.A. Buchmann, C.J.T. Spence, S. Moore, and M. Jermy, "Fabrication of rigid and flexible refractive-index-matched flow phantoms for flow visualisation and optical flow measurements", Exp. Fluids, vol. 52, pp. 1331-1347, 2012.

[http://dx.doi.org/10.1007/s00348-011-1258-0]

[99] G. Porenta, H. Baumgartner, H. Schima, W. Steffen, D. Moertl, P. Probst, and G. Maurer, An in-vitro model of coronary artery stenosis: Influence of stenosis morphology on velocity measurements., IEEE, 2002, pp. 721-724.

[100] A.E. Ensley, P. Lynch, G.P. Chatzimavroudis, C. Lucas, S. Sharma, and A.P. Yoganathan, "Toward designing the optimal total cavopulmonary connection: An in vitro study", Ann. Thorac. Surg., vol. 68 , no. 4 , pp. 1384-1390, 1999.

[http://dx.doi.org/10.1016/S0003-4975(99)00560-3] [PMID: 10543511]

[101] Z.L. Helgeson, J.S. Jenkins, J.P. Abraham, and E.M. Sparrow, "Particle Trajectories and Agglomeration/Accumulation in Branching Arteries subjected to Orbital Atherectomy", Open Biomed. Eng. J., vol. 5 , pp. 25-38, 2011.

[http://dx.doi.org/10.2174/1874120701105010025] [PMID: 21643425]

[102] M. Siebes, C.S. Campbell, and D.Z. D'Argenio, "Fluid dynamics of a partially collapsible stenosis in a flow model of the coronary circulation", J. Biomech. Eng., vol. 118, no. 4, pp. 489-497, 1996. [http://dx.doi.org/10.1115/1.2796035] [PMID: 8950652]

[103] G. Porenta, H. Schima, A. Pentaris, S. Tsangaris, D. Moertl, P. Probst, G. Maurer, and H. Baumgartner, "Assessment of coronary stenoses by Doppler wires: A validation study using in vitro modeling and computer simulations", Ultrasound Med. Biol., vol. 25, no. 5, pp. 793-801, 1999.

[http://dx.doi.org/10.1016/S0301-5629(99)00033-2]

[PMID: 10414896]

[104] N. Benard, D. Coisne, E. Donal, and R. Perrault, "Experimental study of laminar blood flow through an artery treated by a stent implantation: Characterisation of intra-stent wall shear stress", $J$. Biomech., vol. 36, no. 7, pp. 991-998, 2003. [http://dx.doi.org/10.1016/S0021-9290(03)00068-X]

[PMID: 12757808]

[105] T.L. Poepping, H.N. Nikolov, R.N. Rankin, M. Lee, and D.W. Holdsworth, "An in vitro system for Doppler ultrasound flow studies in the stenosed carotid artery bifurcation", Ultrasound Med. Biol., vol. 28 , no. 4, pp. 495-506, 2002.

[http://dx.doi.org/10.1016/S0301-5629(02)00479-9] [PMID: 12049963]

[106] A. Subramaniam, and S. Sethuraman, Biomedical Applications of
Nondegradable Polymers., Elsevier Inc., 2014.

[http://dx.doi.org/10.1016/B978-0-12-396983-5.00019-3]

[107] J.M. Chan, K.H.K. Wong, A.M. Richards, and C.L. Drum, "Microengineering in cardiovascular research: New developments and translational applications", Cardiovasc. Res., vol. 106, no. 1, pp. 9-18, 2015.

[http://dx.doi.org/10.1093/cvr/cvv049] [PMID: 25691539]

[108] S. Halldorsson, E. Lucumi, R. Gómez-Sjöberg, and R.M.T. Fleming, "Advantages and challenges of microfluidic cell culture in polydimethylsiloxane devices", Biosens. Bioelectron., vol. 63, pp. 218-231, 2015.

[http://dx.doi.org/10.1016/j.bios.2014.07.029] [PMID: 25105943]

[109] E. Doutel, J. Carneiro, J.B.L.M. Campos, and J.M. Miranda, "Artificial stenoses for computational hemodynamics", Appl. Math. Model., vol. 59, pp. 427-440, 2018.

[http://dx.doi.org/10.1016/j.apm.2018.01.029]

[110] Y. Yang, X. Liu, Y. Xia, X. Liu, W. Wu, H. Xiong, H. Zhang, L. Xu, K.K.L. Wong, H. Ouyang, and W. Huang, "Impact of spatial characteristics in the left stenotic coronary artery on the hemodynamics and visualization of 3D replica models", Sci. Rep., vol. 7, no. 1, p. $15452,2017$.

[http://dx.doi.org/10.1038/s41598-017-15620-1] [PMID: 29133915]

[111] E. Westein, S. de Witt, M. Lamers, J.M.E.M. Cosemans, and J.W.M Heemskerk, "Monitoring in vitro thrombus formation with novel microfluidic devices", Platelets, vol. 23, no. 7, pp. 501-509, 2012.

[http://dx.doi.org/10.3109/09537104.2012.709653] [PMID: 22873212]

[112] E. Westein, A.D. van der Meer, M.J.E. Kuijpers, J.P. Frimat, A. van den Berg, and J.W.M. Heemskerk, "Atherosclerotic geometries exacerbate pathological thrombus formation poststenosis in a von Willebrand factor-dependent manner", Proc. Natl. Acad. Sci. USA, vol. 110, no. 4, pp. 1357-1362, 2013.

[http://dx.doi.org/10.1073/pnas.1209905110] [PMID: 23288905]

[113] Y. Zheng, J. Chen, M. Craven, N.W. Choi, S. Totorica, A. DiazSantana, P. Kermani, B. Hempstead, C. Fischbach-Teschl, J.A. López, and A.D. Stroock, "In vitro microvessels for the study of angiogenesis and thrombosis", Proc. Natl. Acad. Sci. USA, vol. 109, no. 24, pp. 9342-9347, 2012.

[http://dx.doi.org/10.1073/pnas.1201240109] [PMID: 22645376]

[114] R.G. Mannino, D.R. Myers, B. Ahn, Y. Wang, H. Margo Rollins, H. Gole, A.S. Lin, R.E. Guldberg, D.P. Giddens, L.H. Timmins, and W.A. Lam, "Do-it-yourself in vitro vasculature that recapitulates in vivo geometries for investigating endothelial-blood cell interactions", Sci. Rep., vol. 5, p. 12401, 2015.

[http://dx.doi.org/10.1038/srep12401] [PMID: 26202603]

[115] S. Kefayati, D.W. Holdsworth, and T.L. Poepping, "Turbulence intensity measurements using particle image velocimetry in diseased carotid artery models: effect of stenosis severity, plaque eccentricity, and ulceration", J. Biomech., vol. 47, no. 1, pp. 253-263, 2014. [http://dx.doi.org/10.1016/j.jbiomech.2013.09.007] [PMID: 24182694]

[116] S. Kefayati, J.S. Milner, D.W. Holdsworth, and T.L. Poepping, "Poepping, In vitro shear stress measurements using particle image velocimetry in a family of carotid artery models: Effect of stenosis severity, plaque eccentricity, and ulceration", PLOS $\backslash O N E$, vol. 9, 2014.

[117] T.L. Poepping, R.N. Rankin, and D.W. Holdsworth, "Flow patterns in carotid bifurcation models using pulsed Doppler ultrasound: effect of concentric vs. eccentric stenosis on turbulence and recirculation", Ultrasound Med. Biol., vol. 36, no. 7, pp. 1125-1134, 2010. [http://dx.doi.org/10.1016/j.ultrasmedbio.2010.02.005]

[PMID: 20447759]

[118] A.L. Dicarlo, T. Poepping, and A.F. Set-up, "Investigation of flow and turbulence in carotid artery models of varying compliance using particle image velocimetry",

[http://dx.doi.org/10.1007/978-3-319-19387-8_423]

[119] A.L. DiCarlo, D.W. Holdsworth, and T.L. Poepping, "Study of the effect of stenosis severity and non-Newtonian viscosity on multidirectional wall shear stress and flow disturbances in the carotid artery using particle image velocimetry", Med. Eng. Phys., vol. 65, pp. $8-23,2019$

[http://dx.doi.org/10.1016/j.medengphy.2018.12.023]

[PMID: 30745099]

[120] M.D. Griffith, T. Leweke, M.C. Thompson, and K. Hourigan, "Pulsatile flow in stenotic geometries: Flow behaviour and stability", J. Fluid Mech., vol. 622, pp. 291-320, 2009. [http://dx.doi.org/10.1017/S0022112008005338]

[121] M. de Almeida Monteiro Melo Ferraz, H.H.W. Henning, P. Ferreira da Costa, J. Malda, S. Le Gac, F. Bray, M.B.M. van Duursen, J.F. 
Brouwers, C.H.A. van de Lest, I. Bertijn, L. Kraneburg, P.L.A.M. Vos, T.A.E. Stout, and B.M. Gadella, "Potential health and environmental risks of three-dimensional engineered polymers", Environ. Sci. Technol. Lett., vol. 5, no. 2, pp. 80-85, 2018. [http://dx.doi.org/10.1021/acs.estlett.7b00495] [PMID: 29911125]

[122] P.C. Sousa, F.T. Pinho, M.S.N. Oliveira, and M.A. Alves, "Extensional flow of blood analog solutions in microfluidic devices", Biomicrofluidics, vol. 5, p. 14108, 2011.

[http://dx.doi.org/10.1063/1.3567888] [PMID: 21483662]

[123] P.C. Sousa, F.T. Pinho, M.A. Alves, and M.S.N. Oliveira, "A review of hemorheology: Measuring techniques and recent advances", KoreaAustralia Rheol. J., vol. 28, pp. 1-22, 2016. [http://dx.doi.org/10.1007/s13367-016-0001-z]

[124] O. Maruyama, T. Yamane, N. Tsunemoto, M. Nishida, T. Tsutsui, and T. Jikuya, "A preliminary study of microcapsule suspension for hemolysis evaluation of artificial organs", Artif. Organs, vol. 23, no. 3, pp. 274-279, 1999.

[http://dx.doi.org/10.1046/j.1525-1594.1999.06316.x] [PMID: 10198720]

[125] S.V. Jansen, I. Müller, M. Nachtsheim, T. Schmitz-Rode, and U. Steinseifer, "Ghost Cell Suspensions as Blood Analogue Fluid for Macroscopic Particle Image Velocimetry Measurements", Artif. Organs, vol. 40, no. 2, pp. 207-212, 2016.

[http://dx.doi.org/10.1111/aor.12511] [PMID: 25997837]

[126] J. Calejo, D. Pinho, F.J. Galindo-Rosales, R. Lima, and L. CampoDeaño, "Particulate Blood Analogues Reproducing the Erythrocytes Cell-Free Layer in a Microfluidic Device Containing a Hyperbolic Contraction", Micromachines, vol. 7, no. 1, p. 4, 2015.

[http://dx.doi.org/10.3390/mi7010004] [PMID: 30407376]

[127] B.N. Muñoz-Sánchez, S.F. Silva, D. Pinho, E.J. Vega, and R. Lima, "Generation of micro-sized PDMS particles by a flow focusing technique for biomicrofluidics applications", Biomicrofluidics, vol. 10, no. 1, p. 014122, 2016.

[http://dx.doi.org/10.1063/1.4943007] [PMID: 27042245]

[128] C.F. Anes, D. Pinho, B.N. Muñoz-Sánchez, E.J. Vega, and R. Lima, "Shrinkage and colour in the production of micro-sized \{PDMS particles for microfluidic applications", J. Micromech. Microeng., vol. 28 , p. 75002,2018

[http://dx.doi.org/10.1088/1361-6439/aab7b9]

[129] T.T. Nguyen, Y. Biadillah, R. Mongrain, J. Brunette, J-C. Tardif, and O.F. Bertrand, "A method for matching the refractive index and kinematic viscosity of a blood analog for flow visualization in hydraulic cardiovascular models", J. Biomech. Eng., vol. 126, no. 4, pp. 529-535, 2004.

[http://dx.doi.org/10.1115/1.1785812] [PMID: 15543873]

[130] J.D. Gray, I. Owen, and M.P. Escudier, "Dynamic scaling of unsteady shear-thinning non-Newtonian fluid flows in a large-scale model of a distal anastomosis", Exp. Fluids, vol. 43, pp. 535-546, 2007.

[http://dx.doi.org/10.1007/s00348-007-0317-z]

[131] E. Akagawa, H. Lee, E. Tatsumi, A. Homma, T. Tsukiya, and Y. Taenaka, "Flow visualization for different port angles of a pulsatile ventricular assist device", J. Artif. Organs, vol. 15, no. 2, pp. 119-127, 2012 .

[http://dx.doi.org/10.1007/s10047-011-0614-4] [PMID: 22038496]

[132] V. Deplano, Y. Knapp, L. Bailly, and E. Bertrand, "Flow of a blood analogue fluid in a compliant abdominal aortic aneurysm model: experimental modelling", J. Biomech., vol. 47, no. 6, pp. 1262-1269, 2014.

[http://dx.doi.org/10.1016/j.jbiomech.2014.02.026] [PMID: 24612986]

[133] A.D. Anastasiou, A.S. Spyrogianni, K.C. Koskinas, G.D. Giannoglou, and S.V. Paras, "Experimental investigation of the flow of a blood analogue fluid in a replica of a bifurcated small artery", Med. Eng. Phys., vol. 34, no. 2, pp. 211-218, 2012.

[http://dx.doi.org/10.1016/j.medengphy.2011.07.012] [PMID: 21824798]

[134] F.J.H. Gijsen, E. Allanic, F.N. van de Vosse, and J.D. Janssen, "The influence of the non-Newtonian properties of blood on the flow in large arteries: unsteady flow in a $90^{\circ}$ curved tube", J. Biomech., vol. 32 , no. 7 , pp. $705-713,1999$.

[http://dx.doi.org/10.1016/S0021-9290(99)00014-7]

[PMID: 10400358]

[135] G. Vlastos, D. Lerche, and B. Koch, "The superposition of steady on oscillatory shear and its effect on the viscoelasticity of human blood and a blood-like model fluid", Biorheology, vol. 34, no. 1, pp. 19-36, 1997.

[http://dx.doi.org/10.3233/BIR-1997-34102] [PMID: 9176588]

[136] G. Vlastos, D. Lerche, B. Koch, O. Samba, and M. Pohl, "The effect of parallel combined steady and oscillatory shear flows on blood and polymer solutions", Rheol. Acta, vol. 36, pp. 160-172, 1997.

[http://dx.doi.org/10.1007/BF00366822]

[137] D. Bento, C.S. Fernandes, J.M. Miranda, and R. Lima, "In vitro blood flow visualizations and cell-free layer (CFL) measurements in a microchannel network", Exp. Therm. Fluid Sci., vol. 109, p. 109847 , 2019.

[http://dx.doi.org/10.1016/j.expthermflusci.2019.109847]

[138] H. Sun, M. Björnmalm, J. Cui, E.H.H. Wong, Y. Dai, Q. Dai, G.G. Qiao, and F. Caruso, "Structure Governs the Deformability of Polymer Particles in a Microfluidic Blood Capillary Model", ACS Macro Lett., vol. 4, pp. 1205-1209, 2015.

[http://dx.doi.org/10.1021/acsmacrolett.5b00591]

[139] T.W. Secomb, and A.R. Pries, "Blood viscosity in microvessels: experiment and theory", C. R. Phys., vol. 14, no. 6, pp. 470-478, 2013. [http://dx.doi.org/10.1016/j.crhy.2013.04.002] [PMID: 25089124]

[140] R. Lima, T. Ishikawa, Y. Imai, and T. Yamaguchi, "Blood flow behavior in microchannels: Past, current and future trends, Single Two-Phase Flows Chem", Biomed. Eng. (N.Y.), pp. 513-547, 2012. [http://dx.doi.org/10.2174/978160805295011201010513]

[141] N. Maeda, "Erythrocyte rheology in microcirculation", Jpn. J. Physiol., vol. 46, no. 1, pp. 1-14, 1996.

[http://dx.doi.org/10.2170/jjphysiol.46.1] [PMID: 8743714]

[142] S.O. Catarino, R.O. Rodrigues, D. Pinho, J.M. Miranda, G. Minas, and R. Lima, "Blood Cells Separation and Sorting Techniques of Passive Microfluidic Devices: From Fabrication to Applications", Micromachines, vol. 10, no. 9, p. 593, 2019. [http://dx.doi.org/10.3390/mi10090593] [PMID: 31510012]

[143] D. Pinho, V. Carvalho, I.M. Gonçalves, S. Teixeira, and R. Lima, "Visualization and measurements of blood cells flowing in microfluidic systems and blood rheology: A personalized medicine perspective", J. Pers. Med., vol. 10, p. 249, 2020.

[http://dx.doi.org/10.3390/jpm10040249]

[144] R. Lima, T. Ishikawa, Y. Imai, M. Takeda, S. Wada, and T. Yamaguchi, "Radial dispersion of red blood cells in blood flowing through glass capillaries: the role of hematocrit and geometry", $J$. Biomech., vol. 41, no. 10, pp. 2188-2196, 2008.

[http://dx.doi.org/10.1016/j.jbiomech.2008.04.033] [PMID: 18589429]

[145] R. Lima, T. Ishikawa, Y. Imai, M. Takeda, S. Wada, and T. Yamaguchi, "Measurement of individual red blood cell motions under high hematocrit conditions using a confocal micro-PTV system", Ann. Biomed. Eng., vol. 37, no. 8, pp. 1546-1559, 2009.

[http://dx.doi.org/10.1007/s10439-009-9732-z] [PMID: 19521772]

[146] N. Doshi, A.S. Zahr, S. Bhaskar, J. Lahann, and S. Mitragotri, "Red blood cell-mimicking synthetic biomaterial particles", Proc. Natl. Acad. Sci. USA, vol. 106, no. 51, pp. 21495-21499, 2009.

[http://dx.doi.org/10.1073/pnas.0907127106] [PMID: 20018694]

[147] S. She, Q. Li, B. Shan, W. Tong, and C. Gao, "Fabrication of redblood-cell-like polyelectrolyte microcapsules and their deformation and recovery behavior through a microcapillary", Adv. Mater., vol. 25, no. 40, pp. 5814-5818, 2013.

[http://dx.doi.org/10.1002/adma.201302875] [PMID: 23943540]

[148] X. Ju, X. Wang, Z. Liu, R. Xie, W. Wang, and L. Chu, "Red-bloodcell-shaped chitosan microparticles prepared by electrospraying", Particuology, vol. 30, pp. 151-157, 2017.

[http://dx.doi.org/10.1016/j.partic.2016.05.011]

[149] D. Pinho, L. Campo-Deaño, R. Lima, and F.T. Pinho, "In vitro particulate analogue fluids for experimental studies of rheological and hemorheological behavior of glucose-rich RBC suspensions", Biomicrofluidics, vol. 11, no. 5, p. 054105, 2017.

[http://dx.doi.org/10.1063/1.4998190] [PMID: 28966701]

[150] K. Chen, T.J. Merkel, A. Pandya, M.E. Napier, J.C. Luft, W. Daniel, S. Sheiko, and J.M. DeSimone, "Low modulus biomimetic microgel particles with high loading of hemoglobin", Biomacromolecules, vol. 13, no. 9 , pp. $2748-2759,2012$.

[http://dx.doi.org/10.1021/bm3007242] [PMID: 22852860]

[151] J. Cui, M. Björnmalm, K. Liang, C. Xu, J.P. Best, X. Zhang, and F. Caruso, "Super-soft hydrogel particles with tunable elasticity in a microfluidic blood capillary model", Adv. Mater., vol. 26, no. 43, pp. 7295-7299, 2014.

[http://dx.doi.org/10.1002/adma.201402753] [PMID: 25209733]

[152] A.C. Anselmo, M. Zhang, S. Kumar, D.R. Vogus, S. Menegatti, M.E. Helgeson, and S. Mitragotri, "Elasticity of nanoparticles influences their blood circulation, phagocytosis, endocytosis, and targeting", ACS Nano, vol. 9, no. 3, pp. 3169-3177, 2015.

[http://dx.doi.org/10.1021/acsnano.5b00147] [PMID: 25715979]

[153] L. Zhang, Z. Cao, Y. Li, J-R. Ella-Menye, T. Bai, and S. Jiang, "Softer 
zwitterionic nanogels for longer circulation and lower splenic accumulation", ACS Nano, vol. 6, no. 8, pp. 6681-6686, 2012 [http://dx.doi.org/10.1021/nn301159a] [PMID: 22830983]

[154] O. Maruyama, T. Yamane, M. Nishida, A. Aouidef, T. Tsutsui, T. Jikuya, and T. Masuzawa, "Fractural characteristic evaluation of a microcapsule suspension using a rotational shear stressor", ASAIO J., vol. 48, no. 4, pp. 365-373, 2002.

[http://dx.doi.org/10.1097/00002480-200207000-00007] [PMID: 12141465]

[155] T.T. Nguyen, R. Mongrain, and S. Prakash, "Development of a blood analog for the hemodynamic efficiency evaluation of cardiovascular devices", Proc. Can. Des. Eng. Netw. Conf., 2004 pp. 1-10 Montreal

[156] D.A.M. Carvalho, A.R.O. Rodrigues, V. Faustino, D. Pinho, E.M.S. Castanheira, and R. Lima, "Microfluidic deformability study of an innovative blood analogue fluid based on giant unilamellar vesicles", J. Funct. Biomater., vol. 9, no. 4, pp. 1-11, 2018. [http://dx.doi.org/10.3390/jfb9040070] [PMID: 30518160]

[157] Y. Tamba, H. Terashima, and M. Yamazaki, "A membrane filtering method for the purification of giant unilamellar vesicles", Chem. Phys. Lipids, vol. 164, no. 5, pp. 351-358, 2011.

[http://dx.doi.org/10.1016/j.chemphyslip.2011.04.003] [PMID: 21524642]

[158] T.J. Merkel, S.W. Jones, K.P. Herlihy, F.R. Kersey, A.R. Shields, M.
Napier, J.C. Luft, H. Wu, W.C. Zamboni, A.Z. Wang, J.E. Bear, and J.M. DeSimone, "Using mechanobiological mimicry of red blood cells to extend circulation times of hydrogel microparticles", Proc. Natl. Acad. Sci. USA, vol. 108, no. 2, pp. 586-591, 2011

[http://dx.doi.org/10.1073/pnas.1010013108] [PMID: 21220299]

[159] N. Vilanova, C. Rodríguez-Abreu, A. Fernández-Nieves, and C. Solans, "Fabrication of novel silicone capsules with tunable mechanical properties by microfluidic techniques", ACS Appl. Mater. Interfaces, vol. 5, no. 11, pp. 5247-5252, 2013.

[http://dx.doi.org/10.1021/am4010896] [PMID: 23659612]

[160] Y.H. Choi, K.H. Chung, H.B. Hong, and W.S. Lee, "Production of PDMS microparticles by emulsification of two phases and their potential biological application", Int. J. Polym. Mater. Polym. Biomater., vol. 67, pp. 686-692, 2017.

[http://dx.doi.org/10.1080/00914037.2017.1375494]

[161] D. Pinho, B.N. Muñoz-Sánchez, C.F. Anes, E.J. Vega, and R. Lima, "Flexible PDMS microparticles to mimic RBCs in blood particulate analogue fluids", Mech. Res. Commun., vol. 100, pp. 18-20, 2019. [http://dx.doi.org/10.1016/j.mechrescom.2019.103399]

[162] R. Lima, E.J. Vega, A.S. Moita, J.M. Miranda, D. Pinho, and A.L.N Moreira, "Fast, flexible and low-cost multiphase blood analogue for biomedical and energy applications", Experiments in Fluids., vol. 61, p. 231, 2020.

[http://dx.doi.org/10.1007/s00348-020-03066-7]

\section{(C) 2020 Carvalho et al.}

This is an open access article distributed under the terms of the Creative Commons Attribution 4.0 International Public License (CC-BY 4.0), a copy of which is available at: https://creativecommons.org/licenses/by/4.0/legalcode. This license permits unrestricted use, distribution, and reproduction in any medium, provided the original author and source are credited. 